\title{
Human Properdin Modulates Macrophage: Mycobacterium bovis BCG Interaction via Thrombospondin Repeats 4 and 5
}

\author{
Maha Ahmed Al-Mozaini ${ }^{1,2}$, Anthony G. Tsolaki', Munirah Abdul-Aziz', ${ }^{1,3}$, Suhair M. \\ Abozaid ${ }^{1,2}$, Mohammed N. Al-Ahdal' ${ }^{2}$ Ansar A. Pathan ${ }^{1}$, Valarmathy Murugaiah ${ }^{1}$, Evgeny M. \\ Makarov ${ }^{1}$, Anuvinder Kaur ${ }^{1}$, Robert B. Sim ${ }^{3}$, Uday Kishore ${ }^{1 *}$ and Lubna Kouser ${ }^{1 *}$ \\ ${ }^{1}$ College of Health and Life Sciences, Brunel University London, London, United Kingdom, ${ }^{2}$ Department of Infection and \\ Immunity, King Faisal Specialist Hospital and Research Centre, Riyadh, Saudi Arabia, ${ }^{3}$ Department of Biochemistry, \\ Oxford University, Oxford, United Kingdom
}

OPEN ACCESS

Edited by:

Cees Van Kooten,

Leiden University, Netherlands

Reviewed by:

Michael Kirschfink,

Universität Heidelberg, Germany

Lubka T. Roumenina,

INSERM UMRS 1138, France

*Correspondence:

Uday Kishore

uday.kishore@brunel.ac.uk, ukishore@hotmail.com;

Lubna Kouser

lubna_k@hotmail.co.uk

Specialty section:

This article was submitted to

Molecular Innate Immunity,

a section of the journal

Frontiers in Immunology

Received: 03 July 2017

Accepted: 01 March 2018

Published: 08 May 2018

Citation:

Al-Mozaini MA, Tsolaki AG

Abdul-Aziz M, Abozaid SM,

Al-Ahdal MN, Pathan AA,

Murugaiah V, Makarov EM, Kaur A, Sim RB, Kishore $U$ and Kouser $L$

(2018) Human Properdin

Modulates Macrophage:

Mycobacterium bovis BCG

Interaction via Thrombospondin

Repeats 4 and 5.

Front. Immunol. 9:533.

doi: 10.3389/fimmu.2018.00533
Mycobacterium tuberculosis can proficiently enter macrophages and diminish complement activation on its cell surface. Within macrophages, the mycobacterium can suppress macrophage apoptosis and survive within the intracellular environment. Previously, we have shown that complement regulatory proteins such as factor $\mathrm{H}$ may interfere with pathogen-macrophage interactions during tuberculosis infection. In this study, we show that Mycobacterium bovis BCG binds properdin, an upregulator of the complement alternative pathway. TSR $4+5$, a recombinant form of thrombospondin repeats 4 and 5 of human properdin expressed in tandem, which is an inhibitor of the alternative pathway, was also able to bind to $M$. bovis BCG. Properdin and TSR4+5 were found to inhibit uptake of $M$. bovis BCG by THP-1 macrophage cells in a dose-dependent manner. Quantitative real-time PCR revealed elevated pro-inflammatory responses (TNF- $\alpha, \mathrm{IL}-1 \beta$, and IL-6) in the presence of properdin or TSR $4+5$, which gradually decreased over $6 \mathrm{~h}$. Correspondingly, anti-inflammatory responses (IL-10 and TGF- $\beta$ ) showed suppressed levels of expression in the presence of properdin, which gradually increased over $6 \mathrm{~h}$. Multiplex cytokine array analysis also revealed that properdin and TSR4+5 significantly enhanced the pro-inflammatory response (TNF- $\alpha, I L-1 \beta$, and $\mathrm{IL}-1 \alpha)$ at $24 \mathrm{~h}$, which declined at $48 \mathrm{~h}$, whereas the anti-inflammatory response (IL-10) was suppressed. Our results suggest that properdin may interfere with mycobacterial entry into macrophages via TSR4 and TSR5, particularly during the initial stages of infection, thus affecting the extracellular survival of the pathogen. This study offers novel insights into the non-complement related functions of properdin during host-pathogen interactions in tuberculosis.

Keywords: complement, cytokine, properdin, macrophage, Mycobacterium tuberculosis, Mycobacterium bovis $B C G$, phagocytosis, thrombospondin repeats

\section{INTRODUCTION}

Properdin is an upregulator of the alternative pathway of complement activation. In one of the three pathways of the complement system, the alternative pathway, the activation of the major complement opsonin, C3, is driven by a complex serine protease, C3bBb, also called the C3 convertase, which is bound to the surface of the complement-activating target. To form $\mathrm{C} 3 \mathrm{bBb}$, factor $\mathrm{B}$ associates 
with $\mathrm{C} 3 \mathrm{~b}$ in the presence of $\mathrm{Mg}^{2+}$ and factor $\mathrm{D}$, a serine protease, which cleaves factor $\mathrm{B}$ into $\mathrm{Bb}$ and $\mathrm{Ba}$ fragments producing a $\mathrm{C} 3$ convertase $\mathrm{C} 3 \mathrm{bBb}$ (1). This complex, which has a half-life of $90 \mathrm{~s}$, is stabilized by the binding of properdin, which increases the half-life by 5 - to 10 -fold (2). Furthermore, C3b molecules are generated by $\mathrm{C} 3 \mathrm{bBb}$ and deposited near to the surface-bound convertase leading to the opsonization of the target and formation of $\mathrm{C} 5$ convertase, producing $\mathrm{C} 5 \mathrm{a}$ and $\mathrm{C} 5 \mathrm{~b}$, leading on to the lytic pathway and cell lysis (3).

The monomer of human properdin $(53 \mathrm{kDa})$ has a flexible rodlike structure with a length of $26 \mathrm{~nm}$ and a diameter of $2.5 \mathrm{~nm}$, composed of seven thrombospondin type I repeats (TSR). Each TSR is of about 60 amino acids, typically containing six conserved cysteine residues: these occur in TSR1-TSR6 (4-6), but the N-terminal domain, TSR0, is truncated. TSR4 is crucial for binding to $\mathrm{C} 3 \mathrm{bBb}$ and TSR5 for binding to $\mathrm{C} 3 \mathrm{bBb}$, suggesting that both TSRs may be important for stabilizing the C3 convertase complex (5). Recently, TSR4+5, expressed as a double domain, has been shown to bind to properdin ligands such as $\mathrm{C} 3 \mathrm{~b}$ and inhibit the alternative complement pathway (7). These studies demonstrate the important role that these TSRs may play in the alternative pathway and in their interaction with pathogens.

Properdin circulates in plasma at a concentration of about $4-25 \mu \mathrm{g} / \mathrm{ml}$ existing as cyclic oligomers, dimer, trimer, and tetramer in a ratio of 26:54:20 (4). The dissociation and reassociation of properdin upon denaturation-renaturation cycles stimulated by guanidine or low $\mathrm{pH}$ indicates properdin ratio stability in solution (8). The interaction between properdin monomers involves the $\mathrm{N}$-terminal end of one monomer and the C-terminal end of another (9). Properdin can also bind to microbial surfaces of several pathogens, including Neisseria gonorrhoeae (10), Salmonella typhimurium lipopolysaccharide (LPS), Neisseria meningitidis lipooligosaccharide (11), and Chlamydia pneumoniae (12). Binding of properdin to microbial surfaces results in the recruitment of fluid phase $\mathrm{C} 3 \mathrm{~b}$, inducing assembly of $\mathrm{C} 3$ convertase $\mathrm{C} 3 \mathrm{bBb}$ and causing further deposition of $\mathrm{C} 3 \mathrm{~b}$ on the pathogen surface (13-15), subsequently generating a C5 convertase, MAC formation, and cell lysis. At $10 \mu \mathrm{g} / \mathrm{ml}$, recombinant properdin enhanced complement deposition on $N$. meningitidis and S. pneumoniae and dramatically enhanced serum lysis of these bacteria, and in the mouse model, significantly reduced bacteremia and increased survival rates (16).

Although Mycobacterium tuberculosis and its close-relative Mycobacterium bovis have significant interaction with components of the innate immune system, e.g., toll-like receptors, complement, surfactant proteins SP-A and SP-D (17), the initial stages of tuberculosis pathogenesis remain poorly understood. Many bacteria have evolved mechanisms to evade immune responses: by inhibiting complement activation by proteolytic cleavage of complement proteins, having their own complement inhibitors (18), or binding complement regulatory proteins like factor $\mathrm{H}(15,19)$.

Mycobacterium tuberculosis is a highly specialized intracellular pathogen and may exploit complement proteins to enhance its uptake by macrophages. Although it has been shown that $M$. tuberculosis can activate all three pathways of the complement system $(20,21)$, it is unclear how the pathogen uses complement proteins in tuberculosis pathogenesis. $M$. tuberculosis has been shown to bind to complement receptors (CR) CR1, CR3, and CR4 and gain entryinto macrophages (22-24). There is also evidence that enhanced phagocytosis of $M$. tuberculosis by human alveolar and monocyte-derived macrophages results from C3 opsonization (24). The ability of $M$. tuberculosis to bind to CR3 non-opsonically has also been shown which may be important for bacterial invasion when complement is sparse, for example, in the lung (25). Properdin has recently been considered as a pattern recognition receptor (PRR) on its own, i.e., binding to recognition patterns without need for prior deposition of $\mathrm{C} 3 \mathrm{~b}$ or $\mathrm{C} 3 \mathrm{bBb}$ (26-28). Therefore, we investigated the role of properdin in tuberculosis pathogenesis, by using the model organism M. bovis BCG.

Here, we show, for the first time, that properdin and recombinant form of TSR $4+5$ expressed as a two-module protein binds to M. bovis BCG, demonstrating its role as a soluble PRR. Properdin and TSR $4+5$ were found to inhibit the uptake of $M$. bovis BCG by macrophages during phagocytosis, altering the pro- and antiinflammatory cytokine response, and thus, possibly shaping the adaptive immune response in tuberculosis pathogenesis.

\section{MATERIALS AND METHODS}

\section{Purification of Native Properdin}

The affinity columns, IgG Sepharose and anti-properdin monoclonal antibody Sepharose, were prepared as described previously (7). The IgG-Sepharose column was prepared from human non-immune IgG ( 26 $\mathrm{mg} \mathrm{IgG} / \mathrm{ml}$ of Sepharose) coupled to CNBr-activated Sepharose (GE Healthcare, UK). For preparation of the anti-human properdin column, $\mathrm{CNBr}$-activated Sepharose (GE Healthcare Life Sciences, UK) was used to couple to antiproperdin mouse monoclonal antibody $(2 \mathrm{mg} / \mathrm{ml})$. One liter of human plasma (TCS Biosciences) containing 5 mM EDTA was filtered through Whatman filter paper before applying to IgG Sepharose to deplete C1q (which would otherwise have bound to the IgG on the anti-properdin Sepharose). The column was washed with three bed volume of HEPES buffer (10 mM HEPES, $140 \mathrm{mM} \mathrm{NaCl}, 0.5 \mathrm{mM}$ EDTA, and $\mathrm{pH}$ 7.4). Plasma was then applied to the monoclonal anti-properdin column and washed with the same HEPES buffer. Bound properdin was eluted with $3 \mathrm{M} \mathrm{MgCl}_{2}$ and the peak fractions were dialyzed against HEPES buffer overnight at $4^{\circ} \mathrm{C}$. Contaminants were further removed by applying the pooled protein fractions to a HiTrap Q FF-Sepharose (GE Healthcare) ion-exchange column, followed by washing the column with three bed volumes of $50 \mathrm{mM}$ Tris- $\mathrm{HCl}, \mathrm{pH} 7.5$, $50 \mathrm{mM} \mathrm{NaCl}$, and $5 \mathrm{mM}$ EDTA. Properdin did not bind to the Q Sepharose column and appeared in the flow-through free from contaminants as demonstrated by SDS-PAGE.

For the size exclusion chromatography analysis, $50 \mu \mathrm{l}$ of the proteins at the concentrations varying from $0.3 \mathrm{mg} / \mathrm{mL}$ to $1.0 \mathrm{mg} /$ $\mathrm{mL}$ were applied to a TSKgel G2000SWXL, $5 \mu \mathrm{m}, 7.8 \times 300 \mathrm{~mm}$ column (Tosoh Bioscience). The column was equilibrated with buffer containing $50 \mathrm{mM}$ sodium phosphate, pH7.0 and $300 \mathrm{mM}$ $\mathrm{NaCl}$ at the flow rate $0.3 \mathrm{ml} / \mathrm{min}$ using SCL-10Avp HPLC system 
(Shimadzu). The absorbance was detected at 230 and $280 \mathrm{~nm}$. The Bio-Rad Gel Filtration Standard (Cat \# 151-1901) were used for the protein molecular weight calibration of the column.

\section{Expression and Purification of TSR4+5}

The recombinant maltose-binding protein (MBP) fusion proteins MBP-TSR4+5, MBP-TSR4, or MBP-TSR5 were expressed in Escherichia coli as described previously $(7,29)$. The E. coli BL21 bacterial cells (Life Technologies) were grown in $1 \mathrm{~L}$ of Luria-Bertani medium with $100 \mu \mathrm{g} / \mathrm{ml}$ ampicillin, shaking at $37^{\circ} \mathrm{C}$ until an optical density at $600 \mathrm{~nm}\left(\mathrm{OD}_{600}\right)$ of between 0.6 and 0.8 was reached. Protein expression was then induced in the bacterial cell culture with $0.4 \mathrm{mM}$ isopropyl $\beta$-D-1thiogalactopyranoside (IPTG) (Sigma-Aldrich) for $3 \mathrm{~h}$ shaking at $37^{\circ} \mathrm{C}$. The cells were then pelleted at $4,500 \mathrm{rpm}, 4^{\circ} \mathrm{C}$ for $10 \mathrm{~min}$, lysed using $50 \mathrm{ml}$ lysis buffer [ $20 \mathrm{mM}$ Tris- $\mathrm{HCl}, \mathrm{pH}$ 8.0, 0.5 M NaCl, $1 \mathrm{mM}$ EDTA, 0.25\% v/v Tween 20, 5\% v/v glycerol, $100 \mu \mathrm{g} / \mathrm{ml}$ lysozyme (Sigma-Aldrich), and $0.1 \mathrm{mM}$ phenylmethanesulfonyl fluoride (Sigma-Aldrich)], and incubated for $1 \mathrm{~h}$ at $4^{\circ} \mathrm{C}$ on a rotary shaker. The cell lysate was then sonicated using a Soniprep 150 (MSE, London, UK) at $60 \mathrm{~Hz}$ for $30 \mathrm{~s}$ with an interval of $2 \mathrm{~min}$ ( 12 cycles) and then centrifuged at $13,000 \mathrm{rpm}$ for $15 \mathrm{~min}$ at $4^{\circ} \mathrm{C}$. The supernatant was diluted five-fold with buffer A (20 mM Tris-HCl, pH 8.0, $100 \mathrm{mM}$ $\mathrm{NaCl}, 1 \mathrm{mM}$ EDTA, and $0.25 \% \mathrm{v} / \mathrm{v}$ Tween 20 ) and passed through an amylose resin column (25 ml bed) (New England Biolabs) that was equilibrated in buffer A. The affinity column was washed with buffer A without Tween 20 and with $1 \mathrm{M} \mathrm{NaCl}$, 20 mM Tris-HCl, pH 8.0, 1 mM EDTA, followed by buffer B (20 mM Tris- $\mathrm{HCl}, \mathrm{pH} 8.0,100 \mathrm{mM} \mathrm{NaCl}, 1 \mathrm{mM}$ EDTA). The MBP-TSR4+5 fusion protein was eluted with $100 \mathrm{ml}$ of buffer B containing $10 \mathrm{mM}$ maltose (Sigma-Aldrich) (affinity elution buffer). Trace contaminants were further removed by applying the fusion protein to a DEAE Sepharose column. Thus, the affinity purified fusion protein in affinity elution buffer was applied to the ion-exchange $(5 \mathrm{ml}$ bed) column and washed with three column volumes of low salt buffer containing $50 \mathrm{mM}$ Tris- $\mathrm{HCl}$, $\mathrm{pH}$ 7.5, $100 \mathrm{mM} \mathrm{NaCl}, 5 \mathrm{mM}$ EDTA, at pH 7.5. After extensive washing with low salt buffer, the fusion protein eluted at $0.2 \mathrm{M}$ $\mathrm{NaCl}$ using a $\mathrm{NaCl}$ gradient $(50 \mathrm{mM}$ to $1 \mathrm{M}$ ). The peak elutions were then passed through Pierce ${ }^{\mathrm{TM}}$ High Capacity Endotoxin Removal Resin (Qiagen) to remove LPS. Endotoxin levels were determined using the QCL-1000 Limulus amebocyte lysate system (Lonza), and the assay was linear over a range of $0.1-1.0$ $\mathrm{EU} / \mathrm{ml}(10 \mathrm{EU}=1 \mathrm{ng}$ of endotoxin). The endotoxin levels were less than $4 \mathrm{pg} / \mu \mathrm{g}$ of the MBP-TSR4+5.

\section{Mycobacterial Cell Culture}

Mycobacterium bovis BCG (Pasteur strain) were grown in liquid culture using Middlebrook 7H9 media (Sigma-Aldrich), supplemented with $0.2 \%(\mathrm{v} / \mathrm{v})$ glycerol, $0.05 \%(\mathrm{v} / \mathrm{v})$ Tween-80, and $10 \%(\mathrm{v} / \mathrm{v})$ albumin dextrose catalase (ADC) (BD BBL, Becton Dickinson). Green fluorescent protein (GFP)-expressing M. bovis $B C G$ (Danish Strain 1331) containing the pGFPHYG2 plasmid was a kind gift from B. Robertson, Imperial College, London, UK. GFP-M. bovis BCG was grown in the above conditions/media but with the addition of $50 \mu \mathrm{g} / \mathrm{ml}$ of hygromycin to maintain the plasmid. Cultures were incubated at $37^{\circ} \mathrm{C}$ with agitation $(\sim 120 \mathrm{rpm})$ for 7-10 days until the bacteria had reached the exponential growth phase at $\mathrm{OD}_{600 \mathrm{~nm}}=0.60-1.00$.

\section{Assay of Human Properdin and TSR4+5 Binding to Mycobacteria}

Mycobacterium bovis BCG, harvested and washed in PBS, was adjusted to a concentration of $1.25 \times 10^{9}$ cells $/ \mathrm{ml}$ in $\mathrm{PBS}\left(\mathrm{OD}_{600}=1\right.$ equates to approximately $1 \times 10^{9} \mathrm{cell} / \mathrm{ml}$ ). Then $200 \mu \mathrm{l}$ of bacterial suspension was dispensed into individual microtiter wells of a 96-well plate (Maxisorp ${ }^{\mathrm{TM}}$, NUNC). Plates were incubated at $4^{\circ} \mathrm{C}$ overnight and washed with buffer 1 [10 mM HEPES pH 7.5, $140 \mathrm{mM} \mathrm{NaCl}, 0.5 \mathrm{mM}$ EDTA, and $100 \mu \mathrm{g} / \mathrm{ml}$ hen ovalbumin (Sigma-Aldrich)]. Wells were blocked for $2 \mathrm{~h}$ at $37^{\circ} \mathrm{C}$ with buffer $1+10 \%(\mathrm{w} / \mathrm{v})$ Marvel Dried Milk powder.

Human properdin (up to $50 \mu \mathrm{g} / \mathrm{ml}$ ) or TSR4+5 (up to $30 \mu \mathrm{g} / \mathrm{ml}$ ) were added, in two-fold serial dilutions $(100 \mu \mathrm{l} /$ well $)$ in buffer 1 and incubated for $2 \mathrm{~h}$ at $37^{\circ} \mathrm{C}$. Individual TSR 4 and TSR5 proteins, MBP and BSA were used as negative controls. Microtiter wells were washed three times with buffer 1 . Mouse antiproperdin monoclonal antibody $(1.19 \mathrm{mg} / \mathrm{ml})$ diluted $1 / 2,500$ in buffer 1 (29) was added to the wells containing properdin. Mouse anti-MBP monoclonal antibody (Sigma-Aldrich) was added to wells containing TSR4+5, TSR4 and TSR5, diluted $1 / 5,000$ in buffer 1 , and incubated for $1 \mathrm{~h}$ at $37^{\circ} \mathrm{C}$. For the BSA negative control, mouse anti-BSA monoclonal antibody (SigmaAldrich) was used (1/5,000 dilution). Plates were washed an additional three times in buffer 1 and then incubated with goat anti-mouse IgG-horseradish peroxidase conjugate (SigmaAldrich), diluted 1/5,000 in buffer 1 . The substrate $p$-nitrophenol phosphate (Sigma-Aldrich) was then added to each well, and the plates read at $405 \mathrm{~nm}$.

\section{Fluorescence Microscopy for TSR4+5 Binding to Mycobacteria}

Mycobacterium bovis BCG bacteria (approximately $10^{6}$ cells) were spotted on poly-L-lysine coated microscope slides (SigmaAldrich) and incubated at $37^{\circ} \mathrm{C}$ for cells to adhere. After washing three times with PBS, bacterial cells were then fixed with $4 \%$ paraformaldehyde for $5 \mathrm{~min}$. Slides were washed three times with PBS and then incubated at $37^{\circ} \mathrm{C}$ for $1 \mathrm{~h}$ with 0,1 , or $10 \mu \mathrm{g} / \mathrm{ml}$ of TSR $4+5$, or $10 \mu \mathrm{g} / \mathrm{ml}$ of BSA (negative control) in buffer 1 . Slides were washed three times with PBS, and then the primary monoclonal antibody (mouse anti-MBP) added at 1/500 dilution and incubated for $1 \mathrm{~h}$ at room temperature. After washing three times with PBS, goat anti-mouse conjugated with AlexaFluor488 (1/500 dilution) was added as the secondary antibody and incubated for $1 \mathrm{~h}$ at room temperature. Slides were then washed three times with PBS and mounted with antifade (Citifluor AF3) PBS solution and viewed using a LeicaDM4000 Fluorescence microscope. Images were processed using Image $\mathrm{J}^{1}$

${ }^{1}$ http://imagej.nih.gov/ij. 


\section{Phagocytosis Assay}

THP-1 macrophage cells were cultured in RPMI-1640 (Gibco) (RPMI) containing $10 \%(\mathrm{v} / \mathrm{v})$ fetal bovine serum (FBS) (SigmaAldrich), $2 \mathrm{mM}$ L-glutamine (Sigma-Aldrich), $100 \mathrm{U} / \mathrm{ml}$ penicillin (Sigma-Aldrich), $100 \mu \mathrm{g} / \mathrm{ml}$ streptomycin (Sigma-Aldrich), and $1 \mathrm{mM}$ sodium pyruvate (Sigma-Aldrich) and left to grow in $5 \% \mathrm{CO}_{2}$ at $37^{\circ} \mathrm{C}$ for approximately 3 days before passaging. Cells were resuspended in RPMI and adjusted to $1 \times 10^{6}$ cells/well (in $1.8 \mathrm{ml}$ ) in a 24-well plate. To induce adherence onto the wells, THP-1 cells were treated with $50 \mathrm{ng} / \mathrm{ml}$ of phorbol 12 -myristate 13-acetate (PMA) (Sigma-Aldrich) into RPMI-1640 without FBS, penicillin or streptomycin and left to settle for at least $30 \mathrm{~min}$ before adding $200 \mu \mathrm{l}$ of bacterial culture $\left(1 \times 10^{9}\right.$ bacteria/ml).

$M$. bovis BCG bacteria were pelleted at mid-exponential phase, at an $\mathrm{OD}_{600 \mathrm{~nm}}=0.6-1.0$ by centrifugation at $1,000 \times g$ for $10 \mathrm{~min}$ at $4^{\circ} \mathrm{C}$. The mycobacterial pellet was resuspended in the buffer 1 . This mycobacterial culture was then separated into different microfuge tubes and treated with varying concentrations of properdin $(2$ or $20 \mu \mathrm{g} / \mathrm{ml})$ or MBP-TSR4+5 (1 or $5 \mu \mathrm{g} / \mathrm{ml})$. Control samples were left untreated, and all were incubated for $2 \mathrm{~h}$ at $37^{\circ} \mathrm{C}$ for binding to occur. The mycobacterial suspension was washed once in growth medium before resuspending in RPMI medium without FBS, penicillin, or streptomycin. $200 \mu \mathrm{l}$ of the mycobacterial suspension was added to each well of THP-1 cells. Mycobacterial concentration was adjusted to give approximate multiplicity of infection (MOI) ratio of 10:1.

Plates were gently swirled and incubated at $37^{\circ} \mathrm{C}, 5 \% \mathrm{CO}_{2}$ for up to $48 \mathrm{~h}$ to allow mycobacterial uptake. THP-1 cells were sampled at 15, 30, and $45 \mathrm{~min}$ and 1,2, and $6 \mathrm{~h}$. Supernatants were collected after 24 and $48 \mathrm{~h}$ of incubation for multiplex analysis. Plates were washed three times with PBS to remove extracellular bacteria. THP- 1 cells were then lifted by adding $1 \mathrm{ml}$ of $0.25 \%$ trypsin to the wells and incubated for $10 \mathrm{~min}$ at $37^{\circ} \mathrm{C}, 5 \% \mathrm{CO}_{2}$. THP- 1 cells were collected by centrifugation at $1,000 \times g$ for $10 \mathrm{~min}$ at $4^{\circ} \mathrm{C}$.

To recover and count the ingested mycobacteria, THP-1 cells were lysed by resuspending the cell pellets in $1 \mathrm{ml}$ of sterile water, followed by a series of vortex mixing for $10 \mathrm{~min}$ at room temperature. 24-well plates containing $2 \mathrm{ml}$ Middlebrook 7H10 agar with $10 \%$ Oleic Acid+ADC (OADC) (BD, BBL, Becton Dickinson) were prepared. Four serial 1/10 dilutions were made, and $10 \mu \mathrm{l}$ of the concentrated mycobacterial suspension and diluted suspension from each time point was spotted onto the 7H10 agar wells. The 24-well plates were secured with parafilm and wrapped in aluminum foil, inverted and incubated at $37^{\circ} \mathrm{C}$ for $10-14$ days. Wells were photographed, and the colony-forming unit (CFU) count determined. The same procedure was used to quantify the initial input number of bacteria incubated with THP-1 cells.

\section{Fluorescence Microscopy for Phagocytosis Assay}

THP- 1 cells were cultured as described above and seeded at $1 \times 10^{5}$ cells per $13 \mathrm{~mm}$ coverslip and differentiated with PMA as described above. GFP-expressing M. bovis BCG was incubated with $0,1,10 \mu \mathrm{g} / \mathrm{ml}$ of TSR $4+5$ for $2 \mathrm{~h}$ at $37^{\circ} \mathrm{C}$ in buffer 1 . Cells were also incubated with $10 \mu \mathrm{g} / \mathrm{ml}$ of BSA as a negative control.
TABLE 1 | Primers used for quantitative real-time PCR

\begin{tabular}{lll}
\hline \multicolumn{1}{c}{ Forward primer } & Reverse primer \\
\hline $18 S$ & 5'-ATGGCCGTTCTTAGTTGGTG-3' & 5'-CGCTGAGCCAGTCAGTGTAG-3' \\
IL-1 $\beta$ & 5'-GGACAAGCTGAGGAAGATGC-3' & 5'-TCGTTATCCCATGTGTCGAA-3' \\
IL-6 & 5'-GAAAGCAGCAAAGAGGCACT-3' & 5'-TTCACCAGGCAAGTCTCCT-3' \\
IL-10 & 5'-TTACCTGGAGGAGGTGATGC-3' & 5'-GGCCTTGCTCTTGTITCAC-3' \\
IL-12 & 5'-AACTTGCAGCTGAAGCCATT-3' & 5'-GACCTGAACGCAGAATGTCA-3' \\
TGF- $\beta$ & 5'-GTACCTGAACCCGTGTTCT-3' & 5'-GTATCGCCAGGAATTGTTGC-3' \\
TNF- $\alpha$ & 5'-AGCCCATGTTGTAGCAAACC-3' & 5'-TGAGGTACAGGCCCTCTGAT-3'
\end{tabular}

Cells were washed twice in PBS and then resuspended in plain RPMI media. $1 \times 10^{6}$ GFP-M. bovis BCG was added to the THP- 1 cells (MOI of 10:1) and incubated for phagocytosis for $2 \mathrm{~h}$ at $37^{\circ} \mathrm{C}$. THP-1 cells were then washed three times in PBS to remove extracellular bacteria and then fixed in $4 \%$ paraformaldehyde for 5 min. After washing three times in PBS, THP-1 cells were incubated with $2 \mu \mathrm{g} / \mathrm{ml}$ of AlexaFluor546-conjugated wheat germ agglutinin (Invitrogen) to reveal the plasma membrane. Cells were then washed three times and mounted using Vectashield antifade with DAPI (Vector Labs) to reveal nucleus. Slides were observed under a Leica DM4000 fluorescence microscope at 40x magnification. Images were processed using Image J (see text footnote 1).

\section{Quantitative Real-Time PCR (qPCR) Analysis of mRNA Expression of Cytokines} THP-1 cell pellets were collected from each time point as described above. RNA extraction was performed using the GenElute Mammalian Total RNA Purification Kit (Sigma-Aldrich) according to the manufacturer's protocol. Samples were then treated with DNase I (Sigma-Aldrich) to remove any contaminating DNA according to the manufacturer's protocol. The amount of RNA was measured using the NanoDrop 2000/2000c spectrophotometer (Thermo Fisher Scientific) at $260 \mathrm{~nm}$, and the ratio of absorbance at 260 and $280 \mathrm{~nm}$ was used to assess the purity of the RNA. Complementary DNA (cDNA) was synthesized using High Capacity RNA to cDNA Kit (Applied Biosystems, UK) according to the manufacturer's protocol. Primer sequences (Table 1) were designed and analyzed for specificity using the nucleotide Basic Local Alignment Search Tool and Primer-BLAST. ${ }^{2}$

PCR was performed on all cDNA samples to assess the quality of the cDNA. The qPCR assays were performed for the expression of pro- and anti-inflammatory cytokines. The qPCR reaction consisted of $5 \mu \mathrm{l}$ Power SYBR Green MasterMix (Applied Biosystems), $75 \mathrm{nM}$ of forward and reverse primer, $500 \mathrm{ng}$ template $\mathrm{CDNA}$ in a $10 \mu \mathrm{l}$ final reaction volume. $\mathrm{qPCR}$ was performed in a 7900HT Fast Real-Time PCR System (Applied Biosystems). The initial steps were $2 \mathrm{~min}$ incubation at $50^{\circ} \mathrm{C}$ followed by 10 min incubation at $95^{\circ} \mathrm{C}$, the template was then amplified for 40 cycles under these conditions: $15 \mathrm{~s}$ incubation at $95^{\circ} \mathrm{C}$ and $1 \mathrm{~min}$ incubation at $60^{\circ} \mathrm{C}$. Samples were normalized using the expression of human $18 \mathrm{~S}$ rRNA. Data were analyzed using the relative quantification (RQ) Manager Version 1.2.1 (Applied Biosystems). Cycle threshold (Ct) values for each cytokine target

${ }^{2}$ http://blast.ncbi.nlm.nih.gov/Blast.cgi. 
gene were calculated, and the relative expression of each cytokine target gene was calculated using the RQ value, using the formula: $R Q=2^{-\Delta \Delta C t}$ for each cytokine target gene, and comparing relative expression with that of the $18 \mathrm{~S}$ rRNA constitutive gene product. Assays were conducted twice in triplicate.

\section{Multiplex Analysis}

Supernatants were collected from the phagocytosis assay at 24 and $48 \mathrm{~h}$ to determine the levels of secreted cytokines (IL-6, IL-10, IL-12p40, IL-12p70, IL-1 $\alpha$, IL-1 $\beta$, TNF- $\alpha$, IL-13, IL-15, IL-17A, IL-9, and TNF- $\beta$ ), chemokines (MCP-3, MDC, Eotaxin, Fractalkine, GRO, IL-8, IP-10, MCP-1, and MIP-1 $\alpha$ ), growth factors (IL-2, EGF, FGF-2, G-CSF, GM-CSF, IL-3, IL-4, IL-5, IL-7, and VEGF), and other related ligands and receptors (IFN- $\alpha 2$, IFN- $\Upsilon$, FLT-3L, IL-1RA, and sCD40L). MagPix Milliplex kit (EMD Millipore) was used to measure immune response following the manufacturer's protocol. $25 \mu \mathrm{l}$ of assay buffer was added to each well of a 96-well plate, followed by the addition of $25 \mu \mathrm{l}$ of standard, controls or supernatants of cells treated with M. bovis BCG in the presence or absence of properdin and MBP-TSR4+5.25 $\mu \mathrm{l}$ of magnetic beads coupled to analytes of interest was added in each well and incubated for $18 \mathrm{~h}$ at $4^{\circ} \mathrm{C}$. The 96 -well plate was washed with the assay buffer, and $25 \mu \mathrm{l}$ of detection antibodies was incubated with the beads for $1 \mathrm{~h}$ at room temperature. $25 \mu \mathrm{l}$ of streptavidinphycoerythrin was then added to each well and incubated for $30 \mathrm{~min}$ at room temperature with shaking at $750 \mathrm{rpm}$. Following a washing step, $150 \mu \mathrm{l}$ of sheath fluid was added to each well, and the plate was read using the Luminex Magpix instrument. Assays were conducted in duplicate.

\section{Statistical Analysis}

Analysis of data for statistical significance was conducted using GraphPad Prism 6 for Windows (GraphPad Software, Inc.). Statistical analyses were made using two-way ANOVA for mRNA expression data and a one-way ANOVA for the multiplex data. $p$ Values $<0.05$ were considered statistically significant, unless otherwise stated (non-significant).

\section{RESULTS}

\section{Human Properdin and TSR4+5 Bind to Mycobacteria}

Human properdin was purified from human plasma. SDS-PAGE, followed by western blotting using antihuman properdin polyclonal antibodies, showed a distinct band at $55 \mathrm{kDa}$ (Figure 1A), which was the expected molecular weight of the glycosylated monomer. The two biologically active modules of properdin TSR4 and TSR5 were expressed together in tandem as previously described, fused to MBP (7), and is also shown on an SDS-PAGE gel, which has a molecular weight of $55 \mathrm{kDa}$ (Figure 1B). Using gel filtration chromatography, we found that human properdin eluted as a mixture of monomer, dimer and trimer; a negligible amount probably formed aggregates. Nearly $60 \%$ of MBP-TSR $4+5$ appeared as a monomer while nearly $40 \%$ was found to migrate as a dimer (data not shown).

The binding of properdin to M. bovis BCG was observed to be in a dose-dependent manner; BSA was used as a negative control that showed almost no binding (Figure 2A). TSR4+5 binding was also observed to be in a dose-dependent manner. $\mathrm{MBP}$ was used as a negative control (Figure 2B). The two binding curves cannot be compared quantitatively, as different detection antibodies were used. Because the MBP-TSR4+5 recombinant protein and properdin monomer have about the same molecular weight, $5 \mu \mathrm{g}$ of TSR $4+5$ corresponds in molar terms to about $5 \mu \mathrm{g}$ of properdin monomer (Figures 1A,B). The binding of a mixture of the two separately expressed TSR4, and TSR5 is much lower than that of the combined expressed TSR $4+5$ (Figure 2B). For this comparison, the same detection antibody was used. These results suggest that both TSR4 and TSR5 modules contribute to the interaction with $M$. bovis BCG, and that TSR4+5 binds
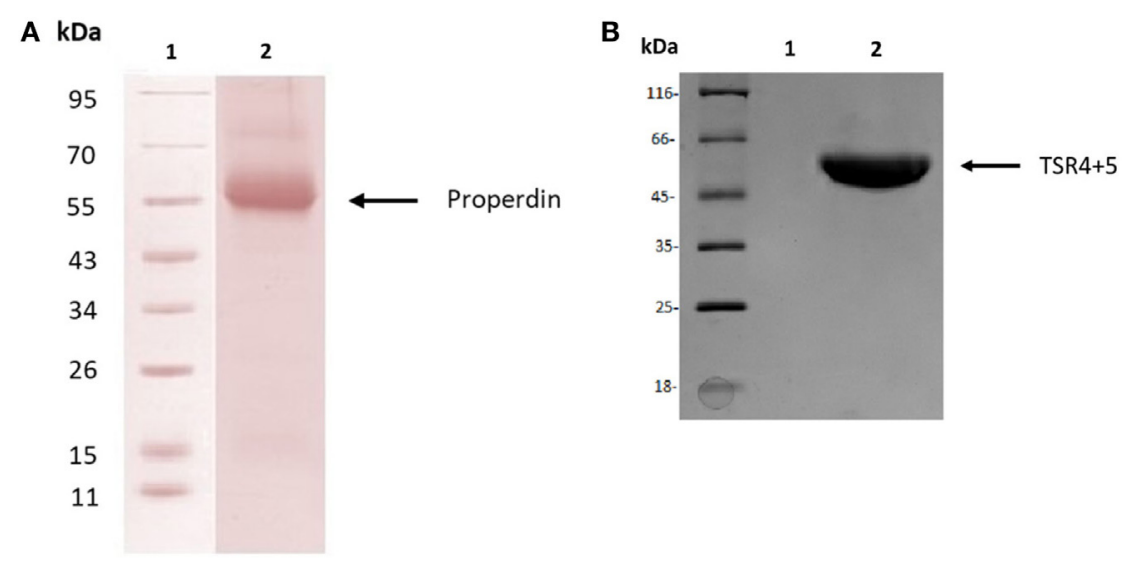

FIGURE 1 | Purified human properdin and recombinant maltose-binding protein (MBP)-thrombospondin repeats (TSR) 4+5. (A) Properdin was purified from human plasma. Filtered plasma was applied to a non-immune lgG-Sepharose column, then to a mouse monoclonal anti-properdin Sepharose column; properdin was eluted with $3 \mathrm{M} \mathrm{MgCl}_{2}$. The eluted samples were dialyzed against HEPES buffer (10 mM HEPES, $140 \mathrm{mM} \mathrm{NaCl,} 0.5 \mathrm{mM} \mathrm{EDTA}, \mathrm{pH} 7.4$ ) overnight at $4{ }^{\circ} \mathrm{C}$. Contaminants were removed by applying the protein to a Q Sepharose column, and the product appears as a single band on SDS-PAGE and western blot at about $55 \mathrm{kDa}$. (B) MBP-TSR4+5 was purified via an amylose resin column, and the purified fusion protein also appears on SDS-PAGE as a band of about $55 \mathrm{kDa}$. 
with similar characteristics to that of whole properdin on M. bovis BCG surface. These results were further confirmed using microscopy where TSR $4+5$ specifically bound to $M$. bovis BCG in a dose-dependent manner (Figure 2C).

\section{Properdin Inhibits Uptake of $M$. bovis BCG by THP-1 Cells}

Properdin inhibited the uptake of $M$. bovis BCG by THP-1 cells. At a concentration of $20 \mu \mathrm{g} / \mathrm{ml}$, uptake of $M$. bovis BCG was significantly reduced by properdin (Figure 3A). TSR4+5 was also able to substantially inhibit uptake of $M$. bovis BCG by THP-1 cells (Figure 3B). The effect of properdin and
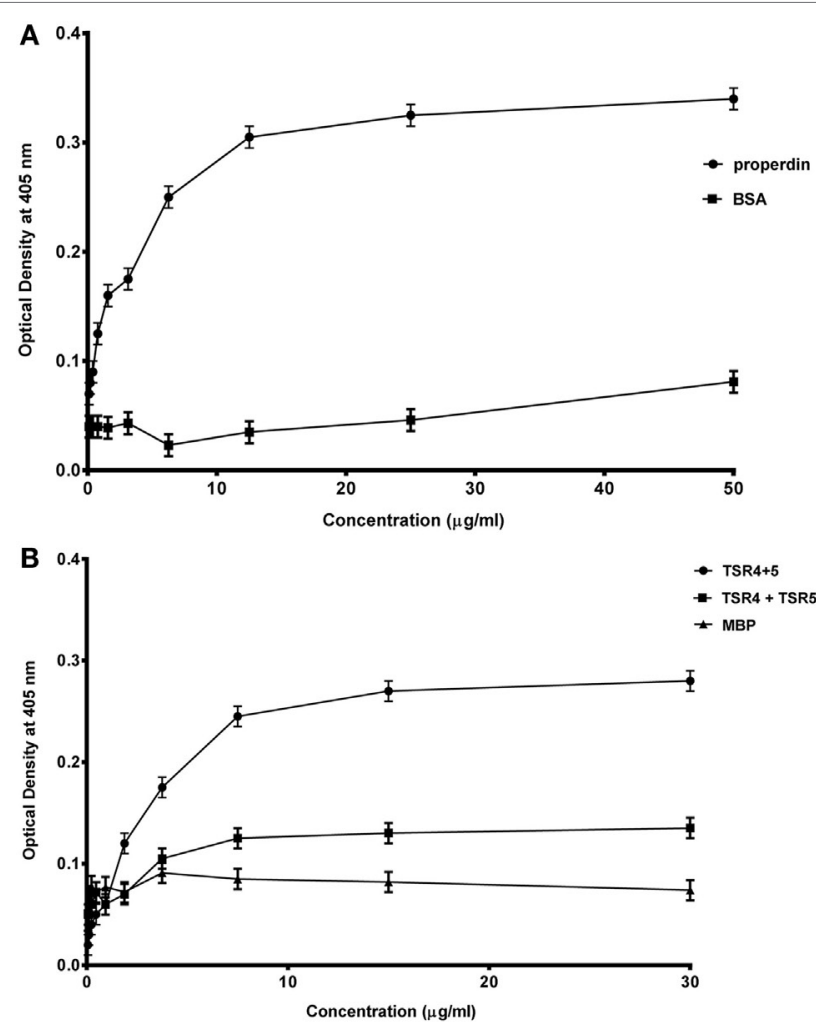

C

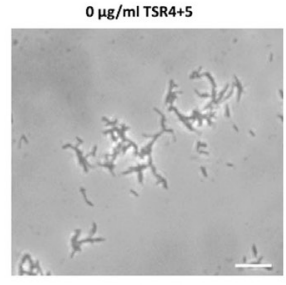
$1 \mu \mathrm{g} / \mathrm{ml} \mathrm{TSR} 4+5$

$10 \mu \mathrm{g} / \mathrm{ml} \mathrm{BSA}$
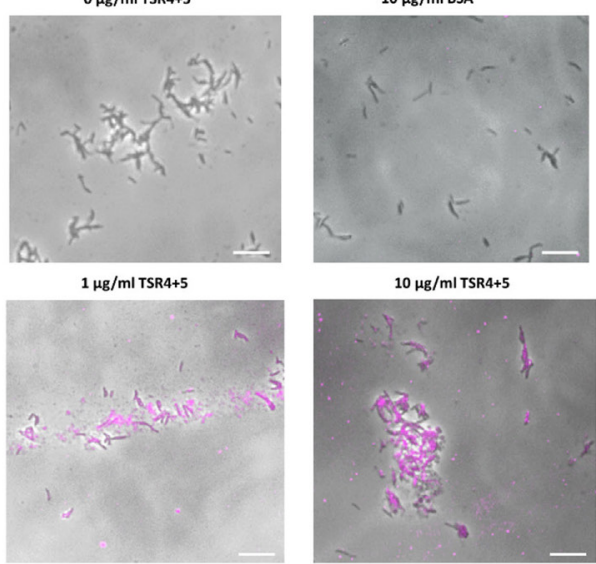

$10 \mu \mathrm{g} / \mathrm{ml} \mathrm{TSR} 4+5$

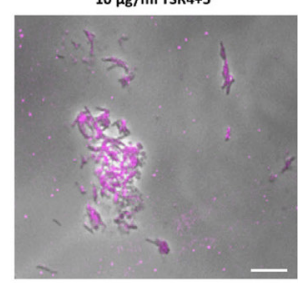

FIGURE 2 | Continued

FIGURE 2 | Human properdin binds mycobacteria via thrombospondin repeats (TSR) $4+5$. (A) Properdin binding to mycobacteria; BSA was used as a negative control protein. (B) Comparison between TSR4 +5 and individual TSR4 and TSR5 binding to mycobacteria; maltose-binding protein (MBP) as negative control. Assays were conducted in $10 \mathrm{mM} \mathrm{HEPES,} 140 \mathrm{mM} \mathrm{NaCl}$, $0.5 \mathrm{mM} \mathrm{CaCl}_{2}+0.5 \mathrm{mM} \mathrm{MgCl}_{2}, 100 \mu \mathrm{g} / \mathrm{ml}$ hen ovalbumin, and $\mathrm{pH} 7.5$. Serial dilutions of properdin were incubated in mycobacteria coated wells followed by incubation with mouse anti-properdin monoclonal antibody and mouse anti-BSA monoclonal antibody, respectively; serial dilutions of TSR4+5, TSR4 or TSR5 were incubated in another set of mycobacteria coated wells followed by incubation with mouse anti-MBP monoclonal antibody. Anti-mouse lgG conjugated with alkaline phosphatase and substrate $p$-nitrophenol phosphate were incubated in both sets of wells, and the color was measured at $405 \mathrm{~nm}$ using a plate reader. Assay was conducted in quadruplicate. Error bars represent SD. (C) Differential direct binding of 0,1 , and $10 \mu \mathrm{g} / \mathrm{ml}$ of TSR $4+5$ to Mycobacterium bovis BCG. $10 \mu \mathrm{g} / \mathrm{ml}$ of BSA was used as a negative control. Cells were incubated for $2 \mathrm{~h}$ with either TSR4+5 or BSA. Cells were washed, fixed, and stained with mouse anti-MBP monoclonal antibody followed by goat anti-mouse 1gG-conjugated with AlexaFluor488. Images are shown as single sections taken using a Leica DM4000 microscope; bar scale $10 \mu \mathrm{m}$.

TSR $4+5$ on the phagocytosis of $M$. bovis BCG was dose dependent. The input number of $M$. bovis BCG was about $7.8 \times 10^{6} \mathrm{CFU} /$ $\mathrm{ml}$, which was the total number of bacteria added to THP-1 cells. Without properdin or TSR4+5, $5.0 \times 10^{6} \mathrm{CFU} / \mathrm{ml}$ of $M$. bovis BCG was phagocytosed which was approximately $66 \%$ efficiency of phagocytosis compared with the input number. At the highest concentration tested, properdin showed an inhibition of uptake of approximately $60 \%$ compared with $M$. bovis BCG with no properdin (Figure 3A). For TSR4+5, the effect on $M$. bovis BCG was slightly lower at approximately $40 \%$ inhibition (Figure 3B). These results were also confirmed by microscopy, with TSR $4+5$ having a suppressive effect on the uptake of GFP-expressing $M$. bovis BCG by THP-1 cells (Figure 3C). PMA stimulation was used to induce differentiation of THP-1 cells before incubation with $M$. bovis BCG. PMA has been shown to activate protein kinase $\mathrm{C}$ and increase cell adherence and expression of surface markers associated with macrophage differentiation (30). These data show that (i) properdin has an anti-opsonic effect on $M$. bovis BCG, inhibiting phagocytosis; and (ii) TSR4+5 modules play a major role in this interaction of $M$. bovis BCG and macrophages. These observations demonstrate, for the first time, a novel, non-complement-related role for properdin in host-pathogen interactions in tuberculosis.

\section{Properdin Induces a Pro-Inflammatory Response During the Early Phase of Phagocytosis of $M$. bovis BCG by THP-1 Cells}

The effect of properdin on the inflammatory response during the phagocytosis of $M$. bovis BCG was measured. The gene expression of key pro- and anti-inflammatory cytokines in tuberculosis was determined using quantitative real-time PCR. Our data showed that properdin significantly enhanced the upregulation of pro-inflammatory cytokines TNF- $\alpha$, IL- $1 \beta$, and IL- 6 from THP-1 cells challenged by $M$. bovis BCG (Figure 4A), particularly at the 
initial stage of uptake (within the first hour of phagocytosis), which decreased gradually toward the later stages of phagocytosis. The increase in TNF- $\alpha$ transcript was particularly striking as TNF- $\alpha$ is well known for activating macrophages for killing of intracellular mycobacteria. In addition, TNF- $\alpha$ is a key mediator in the early stages of granuloma formation. By contrast, the

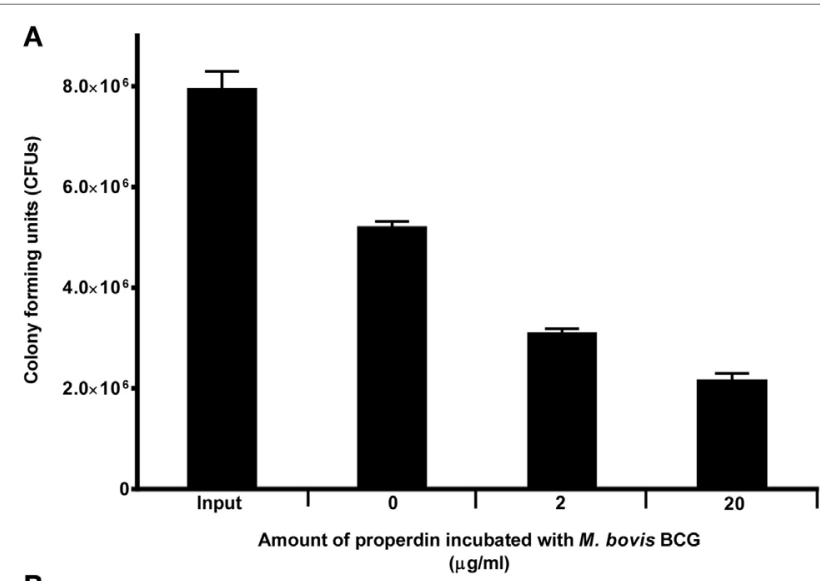

B

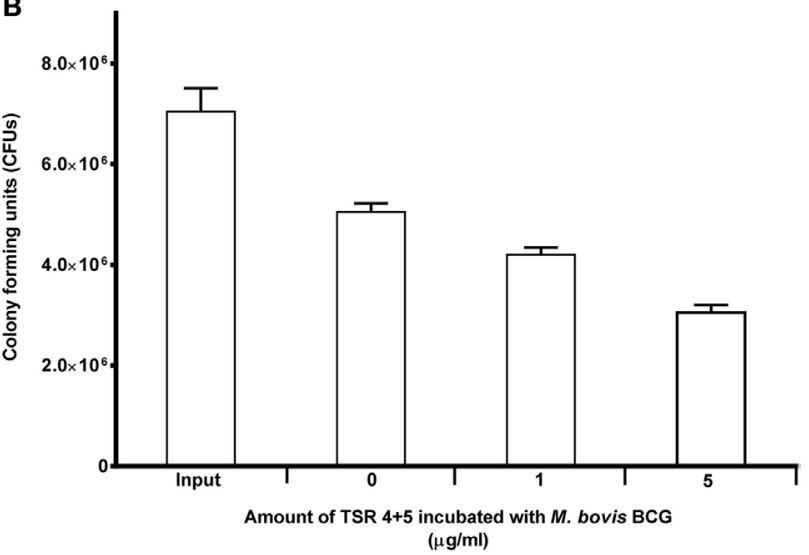

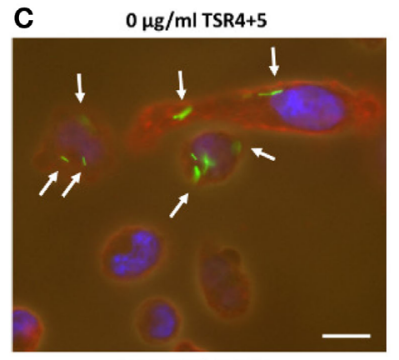

$1 \mu \mathrm{g} / \mathrm{ml} \mathrm{TSR4+5}$
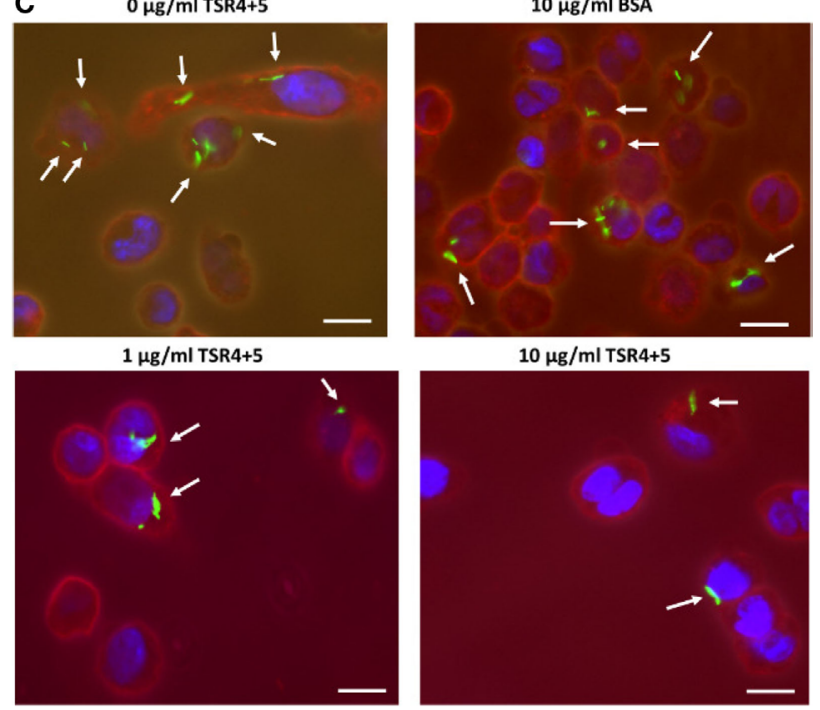

$10 \mu \mathrm{g} / \mathrm{ml} \mathrm{TSR} 4+5$

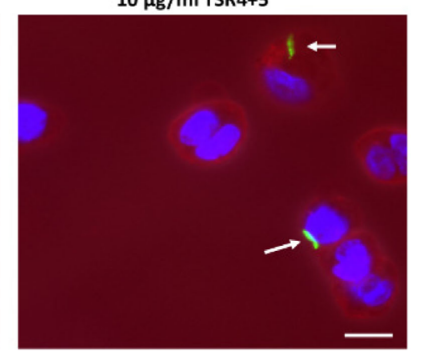

FIGURE 3 | Continued
FIGURE 3 | Effect of properdin and thrombospondin repeats (TSR) 4+5 on the phagocytosis of Mycobacterium bovis BCG by THP-1 cells. (A) M. bovis BCG was treated with properdin at concentrations of 0,2 , and $20 \mu \mathrm{g} / \mathrm{ml}$ or with (B) TSR4 +5 at concentrations 0,1 , and $5 \mu \mathrm{g} / \mathrm{ml}$. The mycobacteria were incubated with macrophage for $2 \mathrm{~h}$. After THP-1 cell lysis, surviving internalized $M$. bovis BCG were measured by plating lysates on $7 \mathrm{H} 10$ media to obtain colony-forming units (CFUs). The input value is the starting number of $M$. bovis BCG added to the THP-1 cells, before phagocytosis. A one-way ANOVA test was performed on the data to determine significant differences in CFU count by properdin or TSR4+5. All comparisons were significant $(p<0.05)$, unless where shown (ns, not significant, $p>0.05)$. Samples were analyzed in triplicate. (C) Differential uptake of GFP-M. bovis BCG by THP-1 macrophages after treatment with 0,1 , and $10 \mu \mathrm{g} / \mathrm{ml}$ of TSR4+5, or $10 \mu \mathrm{g} /$ $\mathrm{ml}$ of BSA, used as a negative control. Cells were incubated for $2 \mathrm{~h}$. Cells were then washed, fixed, and stained with AlexaFluor546-conjugated wheat germ agglutinin to reveal the plasma membrane (red), and the nucleus was stained with DAPI (blue). Images are shown as single sections, taken using a Leica DM4000 microscope; bar scale $10 \mu \mathrm{m}$.

anti-inflammatory cytokines measured from THP-1 cells (IL-10 and TGF- $\beta$ ) were shown to be downregulated in the presence of properdin, when challenged by M. bovis BCG (Figure 4B). IL-12 also appeared to be downregulated (Figure 4A). Properdin, therefore, appears to play an important role in pro-inflammatory cytokine production by macrophages infected by $M$. bovis BCG, which may have significant implications in shaping the adaptive immune response during $M$. tuberculosis infection.

Cytokine gene expression by THP-1 cells infected with $M$. bovis BCG were also studied in the presence of TSR4+5, which revealed that TSR4+5 also has a significant effect on the proinflammatory response. TNF- $\alpha$ was upregulated (Figure 5A), while IL-10 was found to be downregulated (Figure 5B), during the first hour of phagocytosis. IL-12 was also shown to be significantly downregulated (Figure $\mathbf{5 A}$ ). These data mirror the observations for properdin, and hence, validate the importance of TSR $4+5$ in the binding of properdin to M. bovis BCG and in its modulation of the inflammatory response. These data are also similar to recent published observations of another complement regulatory protein, factor $\mathrm{H}$ (19), thus offering potentially novel insights into the involvement of these proteins in host-pathogen interactions in tuberculosis.

\section{Multiplex Analysis of Cytokine Secretion}

The inflammatory response during the phagocytosis of $M$. bovis BCG by THP-1 cells was further determined by measuring the secretion of cytokines, chemokines, and other growth factors using the Multiplex analysis of supernatants collected at 24 and $48 \mathrm{~h}$ post phagocytosis (Figures 6A-D). The secretion of pro-inflammatory cytokines TNF- $\alpha$, IL- $1 \beta$, and IL- $1 \alpha$ was significantly enhanced by treatment with properdin or TSR $4+5$ at the $24 \mathrm{~h}$ time point (Figure 6A). The enhancement of these pro-inflammatory cytokines can be critical for controlling mycobacterial infection, particularly in the formation of the granuloma. However, by $48 \mathrm{~h}$, there was a decrease in the production of pro-inflammatory cytokines (IL-6, IL-12p40, IL-12p70, IL- $1 \alpha$, IL-1 $\beta$, TNF- $\alpha$, IL-13, IL-15, and IL-9) in the presence of properdin- and TSR4+5-treated $M$. bovis BCG (Figure 6A). Properdin and TSR $4+5$ also downregulated the 


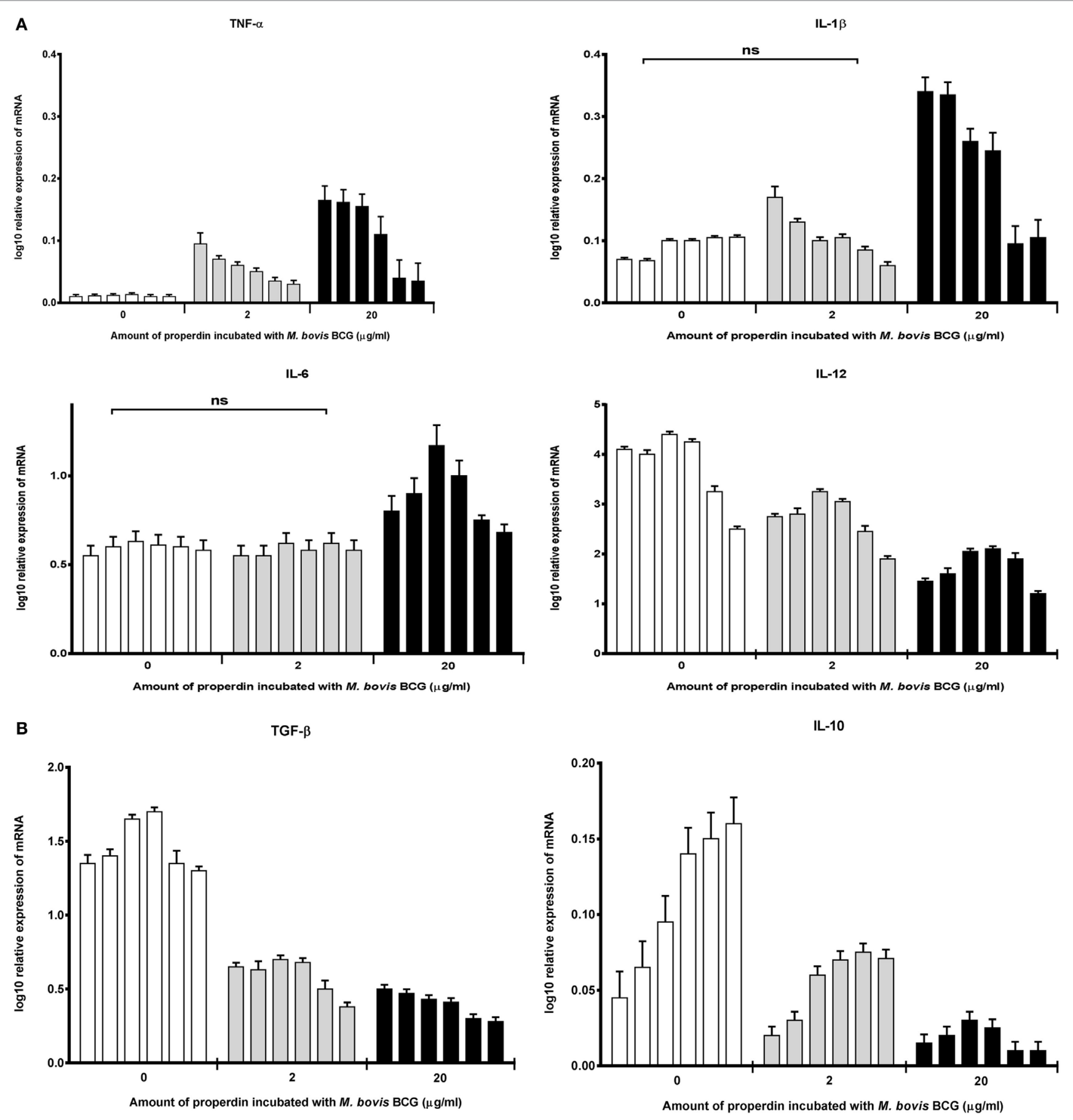

FIGURE 4 | Temporal mRNA expression profile of cytokines produced by THP-1 cells incubated with different concentrations of properdin and Mycobacterium bovis BCG. (A) Pro-inflammatory cytokines: TNF- $\alpha$, IL-1 $\beta$, IL-6, and IL-12; (B) anti-inflammatory cytokines: TGF- $\beta$ and IL-10. The expression of each cytokine was measured using $\mathrm{qPCR}$, and the relative expression [relative quantification (RQ)] calculated by normalizing the data using human $18 \mathrm{~S}$ rRNA expression as a control. The $R Q$ value was calculated using the formula: $R Q=2^{-\Delta \Delta C t}$. Assays were conducted twice in triplicates. Error bars represent $S D$. A two-way $A N O V A$ test was performed on the data to determine significant differences in expression of cytokine production by properdin. All comparisons were significant $(p<0.05)$, unless where shown (ns, not significant, $p>0.05)$.

anti-inflammatory response such as IL-10 after 24 and $48 \mathrm{~h}$ of phagocytosis, although this was less pronounced for IL-12 at $48 \mathrm{~h}$ (Figure 6A). These observations again mirror the initial responses observed in cytokine gene expression of during the first few hours of phagocytosis, in the presence of properdin or TSR $4+5$ (Figures $5 \mathbf{A}, \mathbf{B}$ ). The effect of properdin and TSR $4+5$ also led to marked downregulation of a number of growth factors MCP-3 (24 h), MDC, Eotaxin, Fractalkine (24 h), GRO 


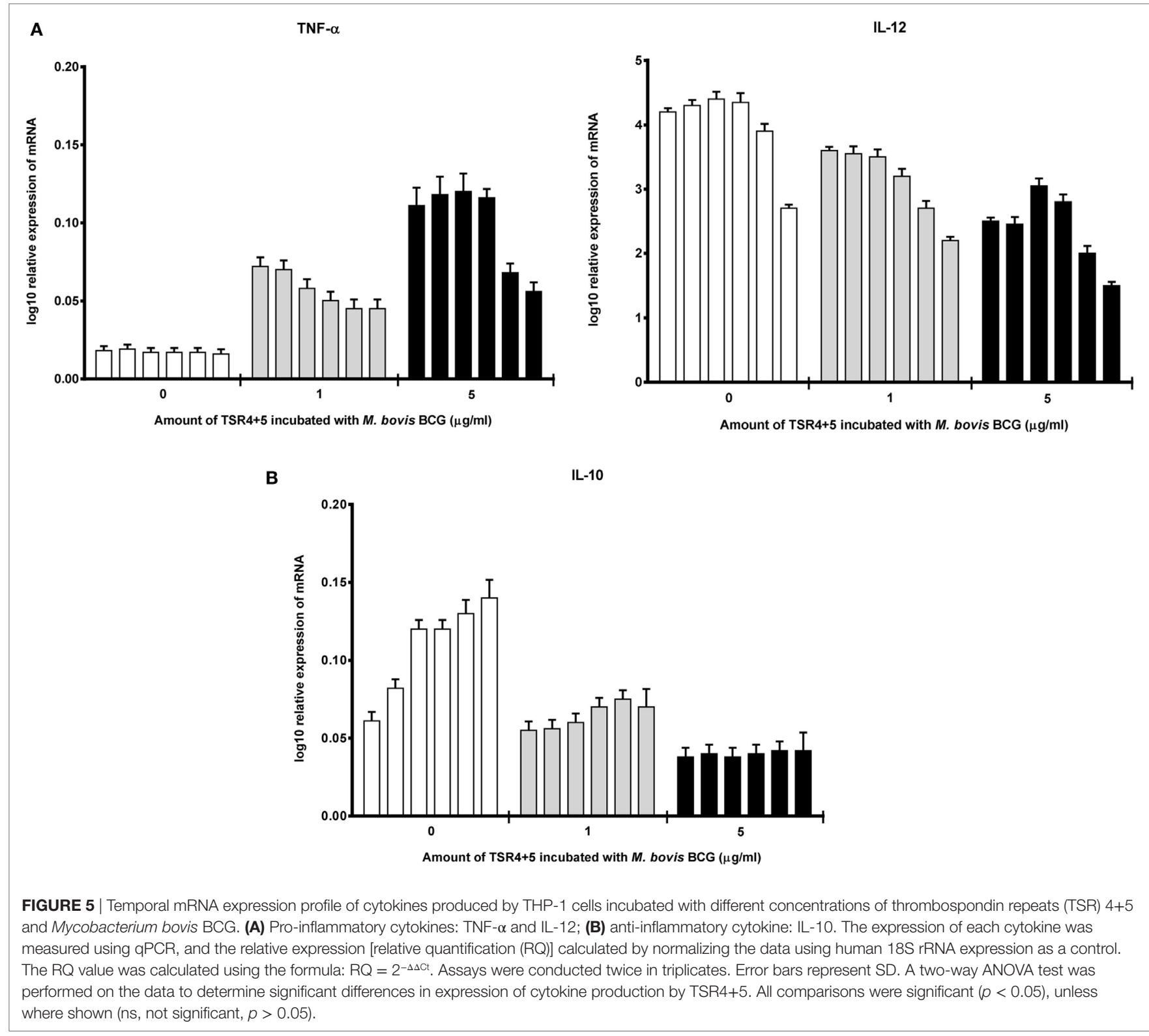

(24 h), IP-10, MCP-1, MIP-1, VEGF, G-CSF (48 h), GM-CSF $(48 \mathrm{~h})$, and VEGF $(24 \mathrm{~h})$ (Figures 6B,C). Additional ligands and receptors (IFN- $\alpha 2$, IFN- $\gamma$, FLT-3L, IL-1RA, and sCD40L) did not show any significant changes (Figure 6D).

\section{DISCUSSION}

We have previously shown that a complement regulatory protein, factor $\mathrm{H}$, can bind to $M$. bovis BCG and inhibit its uptake by THP-1 macrophages (19). Factor $\mathrm{H}$ can also enhance the proinflammatory response during this host-pathogen interaction (19). This study highlighted a novel complement-independent property of factor $\mathrm{H}$ as an anti-opsonin and in the modulation of the inflammatory response against a pathogen. With the goal of further elucidating the role of complement control proteins in the early stages of mycobacterial infection, this study looked at the role of properdin, an upregulator of the alternative complement pathway. Properdin and thrombospondin repeat (TSR) modules TSR4+ 5 were shown to bind to $M$. bovis BCG and inhibit bacterial uptake by THP-1 cells, augmenting the inflammatory response. These observations are similar to what has been observed previously with factor $H$ (19), which is intriguing, since properdin and factor $\mathrm{H}$ have opposing effects on the regulation of complement activation (3). These findings were also consistent with previous reports, which have demonstrated that properdin deficient mice have a reduced M1 (IL-1 $\beta$ ) and increased M2 (arginase-1, MCP1, IL-10) profile, crucial for the tumor microenvironment (31). This suggests that the production of IL- $1 \beta$ and reduction in IL-10 mediated by properdin may be required for protection against $M$. tuberculosis in the initial phase of infection.

The functions of properdin have been extensively investigated within the remit of the complement alternative pathway, and 


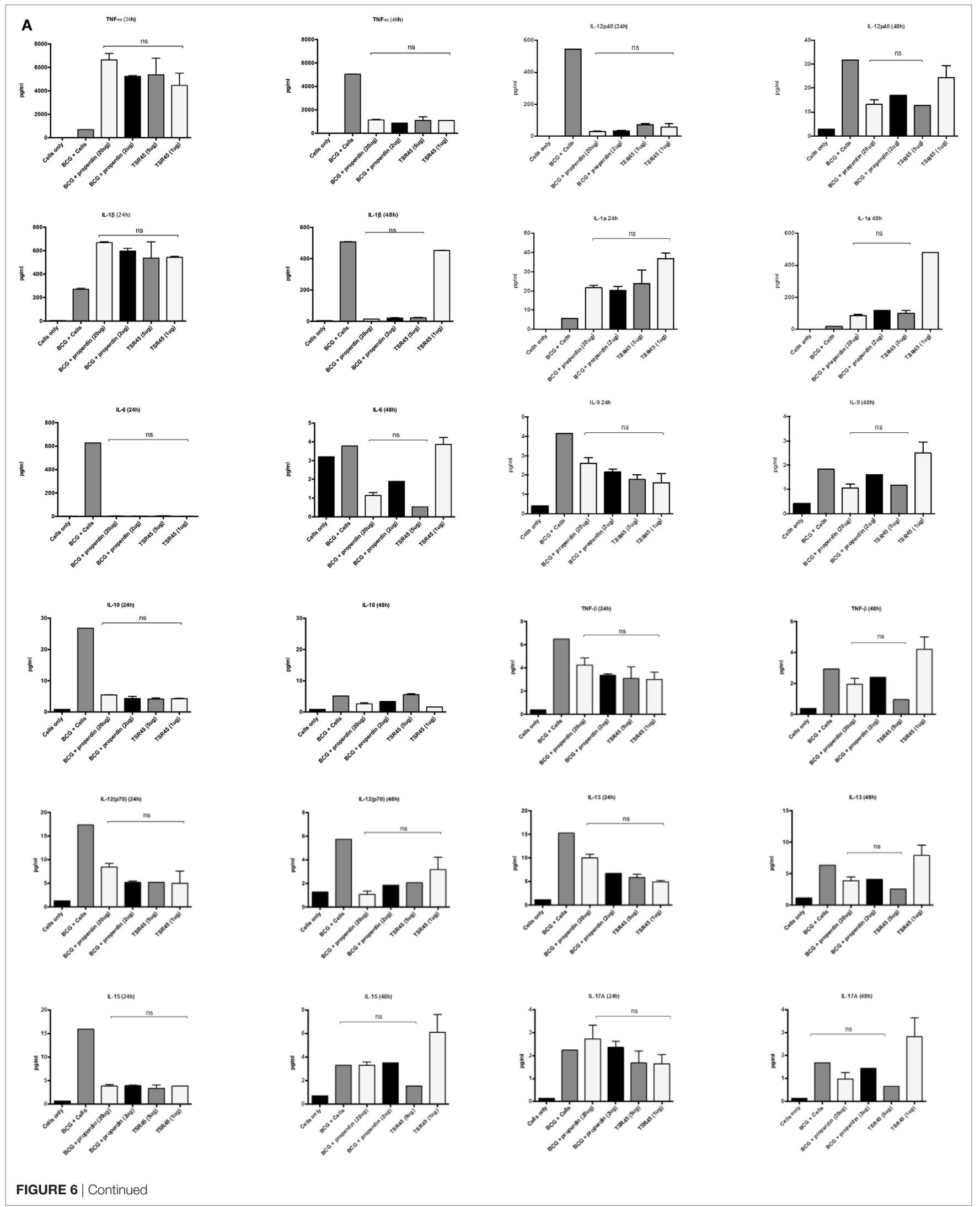



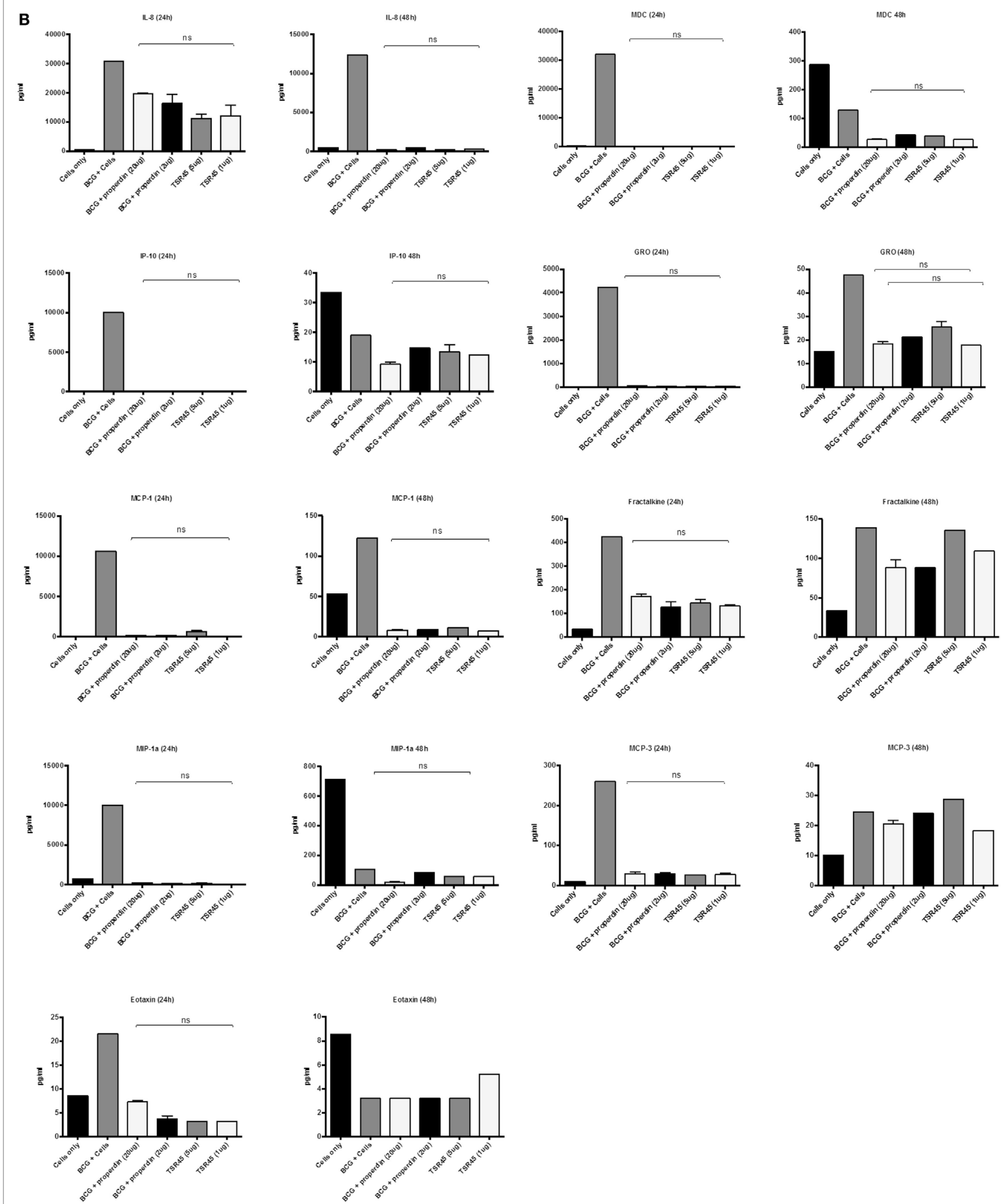

FIGURE 6 | Continued 


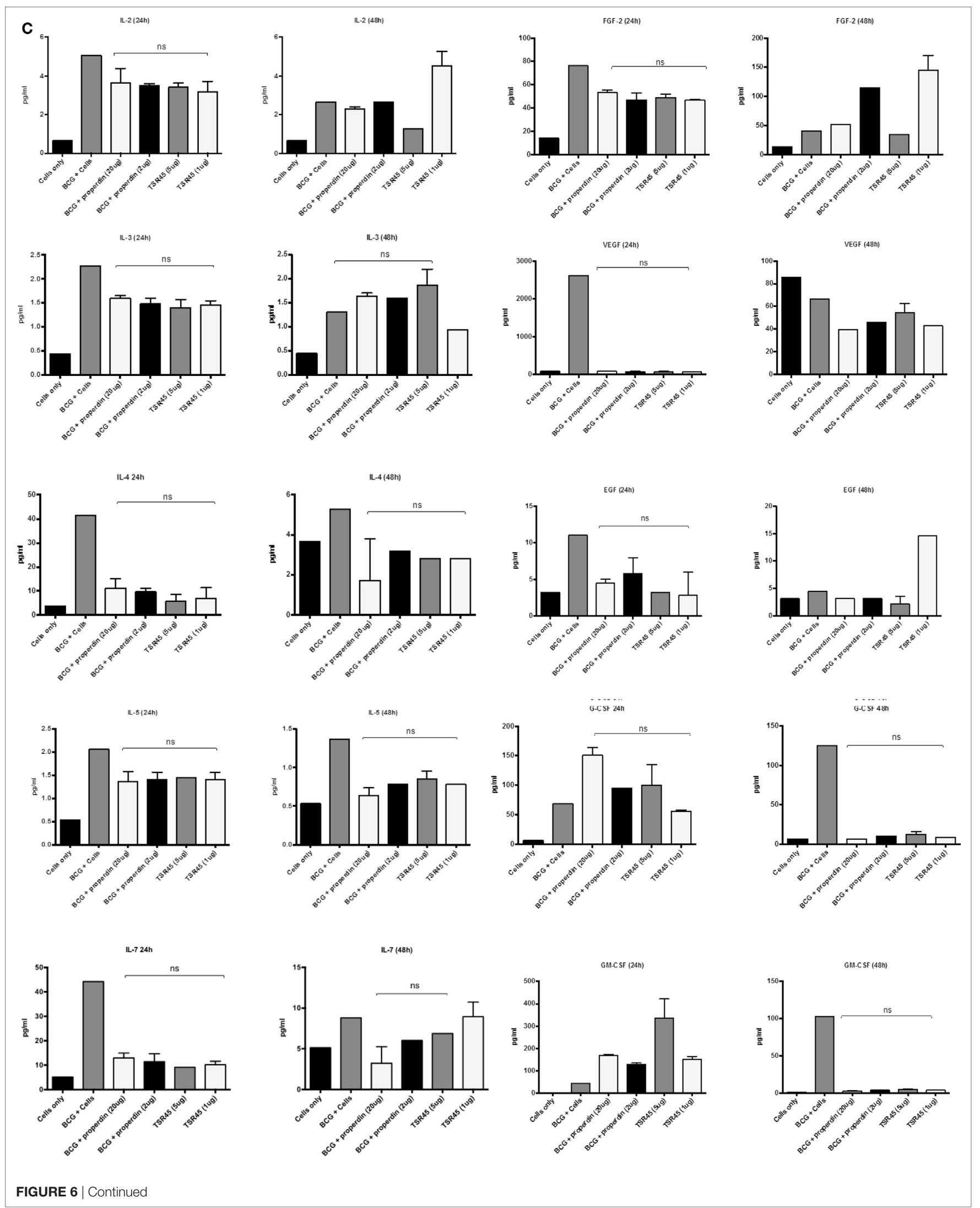



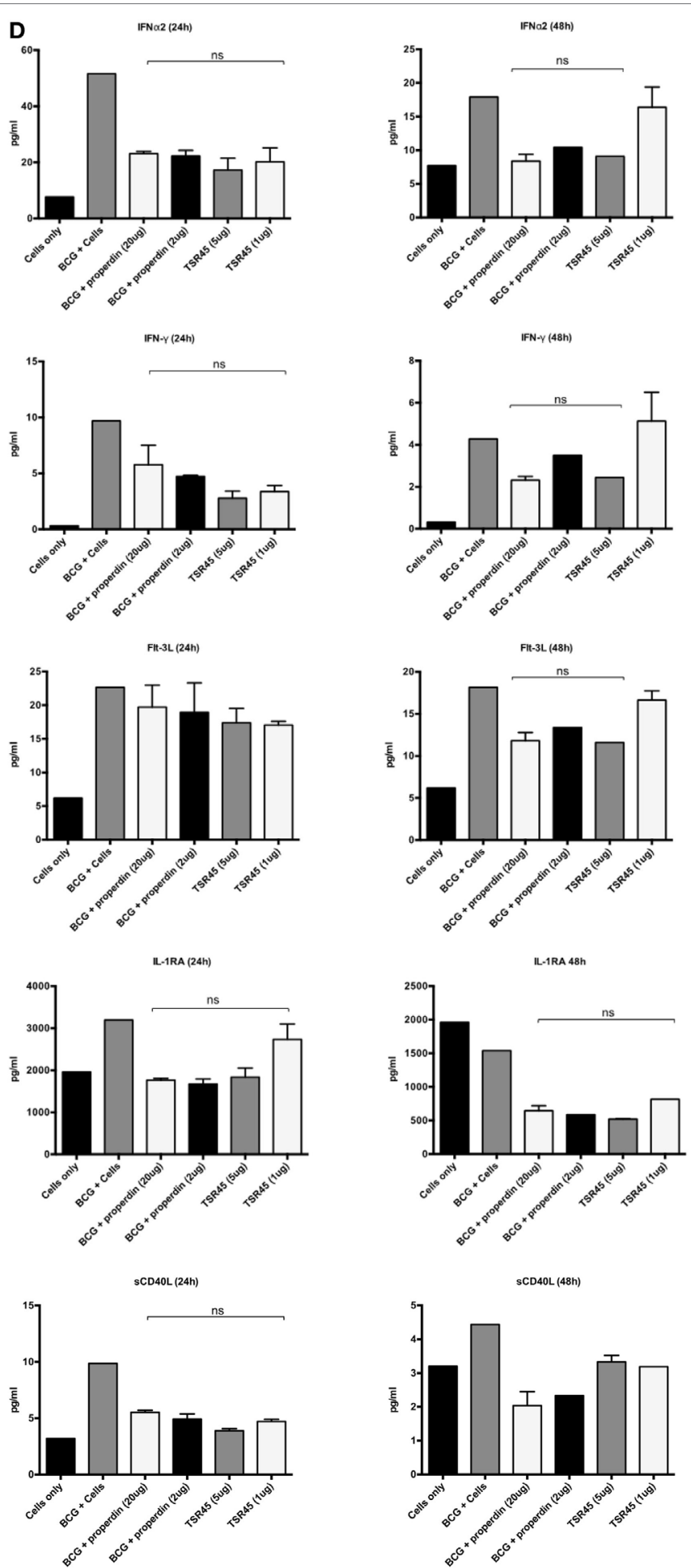

FIGURE 6 | Multiplex cytokine analysis of supernatants collected at 24 and 48 h phagocytosis of Mycobacterium bovis BCG by THP-1 cells incubated with or without properdin and thrombospondin repeats (TSR) $4+5$. The supernatants were collected from phagocytosis assay of $M$. bovis BCG in the presence or absence of properdin and TSR $4+5$ at 24 and $48 \mathrm{~h}$ time point. The levels of cytokine production were measured for (A) (IL-6, IL-10, IL-12p40, IL-12p70, IL-1 $\alpha, \mathrm{IL}-1 \beta, \mathrm{TNF}-\alpha$, IL-13, IL-15, IL-17A, IL-9, and TNF- $\beta$ ), (B) chemokines (MCP-3, MDC, Eotaxin, Fractalkine, GRO, IL-8, IP-10, MCP-1, and MIP-1 $\alpha$ ), (C) growth factors (IL-9, IL-2, EGF, FGF-2, G-CSF, GM-CSF, IL-3, IL-4, IL-5, IL-7, and VEGF), and (D) related ligands and receptors (IFN- $\alpha 2$, IFN- $\gamma$, FLT-3L, IL-1RA, and sCD40L) using multiplex analysis. Error bars represent SD. A one-way ANOVA test was performed on the data to determine significant differences in expression of cytokine production by properdin or TSR4+5. All comparisons were significant $(p<0.05)$, unless where shown (ns, not significant, $p>0.05)$. Supernatants were analyzed in duplicate. 
its involvement with pathogens has largely been characterized as complement dependent. In this study, we aimed to look at the complement-independent interaction of properdin with mycobacteria (i.e., effects in the absence of other complement proteins), with a view to examining its possible role in the pathogenesis of tuberculosis. The role of complement in tuberculosis has been examined, but little is understood about the role of the individual complement proteins in tuberculosis infection, especially complement control proteins. Properdin has been shown to play a role in a number of pathogenic infections such as those by $C$. pneumoniae, in which properdin promotes complement C3b deposition and opsonization (12). A recent study also demonstrated that a low dose of properdin, which is highly polymerized, is able to protect against $N$. meningitidis and Streptococcus pneumoniae, by assembling the alternative complement pathway (16). The central premise in these recent studies is that properdin is an upregulator of the complement alternative pathway, and thus, when in contact with pathogens, the alternative pathway is triggered and stabilized by properdin.

Properdin has also been shown to enhance the uptake of apoptotic T cells by dendritic cells (DCs) and macrophages, thus promoting phagocytosis (27). Properdin may also bind to the DNA found to be exposed on apoptotic and necrotic cells, suggesting that this may also be a crucial site for alternative pathway activation (32). There is recent evidence to suggest that properdin, locally produced by tolerogenic DCs, binds to necrotic cells, confirming its role a pattern recognition molecule of the innate immunity. In addition, properdin is also involved in the interaction of DC and $\mathrm{T}$ cell responses. Interestingly, silencing of properdin by treating DCs with siRNA in the presence/absence of IFN- $\gamma$ reduced the proliferation of allogenic T cells (33). Properdin binds to early apoptotic cells via sulfated GAGs, resulting in C3b deposition and uptake by phagocytes. Activation of neutrophils drives the deposition of properdin, which binds apoptotic T cells. Since properdin has been shown to bind apoptotic cells via GAGs (27) or DNA, it remains unclear what other ligands and receptors are involved in properdin-apoptotic cell interaction. It is likely that properdin as a soluble factor is acting as an adaptor molecule. Furthermore, properdin also binds to NKp46 expressed on natural killer cells, innate lymphoid cells (ILC) 1 and ILC3. This study demonstrated that the control of meningococcal infection was dependent on NKp46 and group 1 ILCs, further elucidating the role of properdin as an independent pattern recognition molecule (34).

In our study, we show that purified native properdin and TSR4+5 bind to $M$. bovis BCG in a dose-dependent manner, suggesting that the binding of properdin to M. bovis BCG may be via TSR4+5. The physiological concentration of properdin in serum is about $25 \mu \mathrm{g} / \mathrm{ml}$ (35). We also demonstrate that coating of M. bovis BCG with properdin inhibits the uptake of the bacterium by THP-1 cells; however, only about $60 \%$ inhibition was achieved at the highest dose of native properdin. TSR $4+5$ was also able to mirror the effects of properdin, in inhibiting the uptake of $M$. bovis BCG by macrophages by up to $40 \%$.

The recruitment of properdin by mycobacteria may be particularly crucial in the initial stages of tuberculosis infection, when after inhalation, the first host cell M. tuberculosis encounters is the alveolar macrophage.
In the lungs, mycobacteria are phagocytosed by alveolar macrophages, which are unable to completely eliminate them, and so produce crucial chemoattractants (36), which recruit inflammatory cells such as neutrophils, macrophages, $\gamma \delta$-T cells, and natural killer cells that stimulate inflammation and tissue remodeling (36-38). Our findings may be indicative of the early inflammatory processes in vivo, involved in granuloma formation, which are nodular-type lesions that cordon-off $M$. tuberculosis infection, and provide an environment for the bacilli to persist and survive as a latent infection. TNF- $\alpha$ and IFN- $\gamma$ are involved in recruitment of cells in the granuloma $(39,40)$. Thus, properdin may play a role in granuloma formation by promoting pro-inflammatory cytokines. Inflammatory balance is essential particularly of Th2/Th1 cytokines, which are required to maintain a protective granuloma (41). This is determined by the balance in IFN- $\gamma /$ TNF- $\alpha$ versus IL-4/IL-10/TGF- $\beta$ within the granuloma. Properdin and TSR4+5 may be implicated in maintaining this balance. It is not known whether complement proteins reside in the granuloma; however, during infection, complement proteins may be produced locally at sites of infection. Properdin may be secreted by neutrophils, monocytes and T cells locally at the site of infection (3). Thus, innate immune molecules residing in or being recruited at sites of infection may play a role in the balance of Th1/Th2, which may cause granuloma necrosis and replication of $M$. tuberculosis (41-43).

TNF- $\alpha$ was dramatically increased in the first $24 \mathrm{~h}$ of phagocytosis in the presence of properdin and TSR4+5, compared to non-treated mycobacteria. TNF- $\alpha$ plays a major role in granuloma formation and our results suggest that properdin may have a role in potentiating the pro-inflammatory response that results in granuloma formation. These observations are further strengthened by the concurrent increase in IL-1 $\alpha$ levels over $24 \mathrm{~h}$ which have been shown to be key in macrophage proliferation and maturation during granuloma formation (44).

During phagocytosis, pro- and anti-inflammatory cytokines were produced by THP-1 cells when treated with properdin or TSR4+5. In the initial stages of infection by M. bovis BCG, pretreated with properdin, during phagocytosis, the expression of TNF- $\alpha$ was significantly enhanced. Other proinflammatory responses that were also elevated in the presence of properdin at initial stages of infection are IL- $1 \beta$ and IL- 6 . IL- $1 \beta$ is a mediator of inflammation and is required for host resistance to M. tuberculosis infection (45). IL-6 is a biomarker for tuberculosis, as increased levels are observed in patients with tuberculosis (46) that is required for a T cell response against $M$. tuberculosis infection $(47,48)$. Conversely, IL-10, IL-12, and TGF- $\beta$ were downregulated by properdin, thus suppressing the anti-inflammatory response. The downregulation of IL-12 by properdin in vivo may suppress the Th1 response. TSR $4+5$ was also able to mimic the cytokine response like properdin, suggesting that the modules responsible for the major part of the interaction with M. bovis BCG may be TSR $4+5$.

Macrophages play a significant role in the innate immune response to pathogens and so are also crucial for an adaptive immune response (49). However, $M$. tuberculosis can evade the innate immune defense, inhibiting phagosome maturation (36), resisting anti-microbial agents damaging the bacterial cell wall 
and facilitating replication within the host and escaping early immune recognition. Thus, these pathogens interfere with the early immune response and the induction of pro-inflammatory cytokines (49).

IL-10 and TGF- $\beta$ suppression by properdin may enhance the clearance of mycobacteria by the host during the early stages of M. tuberculosis infection. After phagocystosis of M. tuberculosis, IL-10 has been shown to block phagolysosome maturation and antigen presentation by macrophages, thus aiding the survival of the pathogen $(50,51)$. Furthermore, IL-10 can inhibit the generation of reactive oxygen and nitrogen intermediates in IFN- $\gamma$ activated macrophages, which are required for intracellular killing $(52,53)$. The enhanced levels of IL-10 and TGF- $\beta$ in the lungs of active tuberculosis patients demonstrate a weakened immune response to $M$. tuberculosis, and hence, a role in the pathogenesis and disease progression $(54,55)$. VEGF was also found to be at a significantly higher level in tuberculosis patients with extrapulmonary tuberculosis (EPTB) than those with pulmonary disease (56). In our study, properdin and TSR $4+5$ seems to result in a marked elevation of VEGF after $48 \mathrm{~h}$. Since our data also shows that mycobacteria have a reduced phagocytosis by macrophages, the resulting extracellular bacteria may be encouraged by VEGF to disseminate. The beneficial effect of properdin may be to inhibit the mechanisms involved in evasion and, thus, facilitate a protective response against mycobacterial infection.

The downregulation of IL- 12 by properdin or TSR $4+5$ may be due to the reduced phagocytosis of $M$. bovis BCG, thus, downregulating the Th1 response. This may be necessary for the Th1/Th2 homeostasis in the protective granuloma $(41,57,58)$. Both IL-10 and TGF- $\beta$ levels were supressed, whilst TNF- $\alpha$ was elevated during the first $24 \mathrm{~h}$ after phagocytosis.

Although $M$. bovis BCG shares 99\% genome homology to $M$. tuberculosis, there are some genetic differences which lead to its avirulence. The major difference between $M$. bovis BCG and $M$. tuberculosis is the large genomic deletion RD1, which causes the loss of various virulent genes coding for proteins such as ESAT-6, CFP-10 and also a bacterial secretion system $(59,60)$. Therefore the findings in our study will need to be validated using virulent strains of $M$. tuberculosis.

Properdin deficiency renders the host susceptible to a range of bacterial infections, especially Neisseria species. Three types of properdin deficiency have been reported: type I (absence of the properdin protein), type 2 (low level of properdin about $1-10 \%$ found in the serum), and type 3 deficiency (normal levels of protein being produced, but functionally defective). The most

\section{REFERENCES}

1. Pangburn MK, Muller-Eberhard HJ. The C3 convertase of the alternative pathway of human complement. Enzymic properties of the bimolecular proteinase. Biochem J (1986) 235:723-30. doi:10.1042/bj2350723

2. Pillemer L, Blum L, Lepow IH, Ross OA, Todd EW, Wardlaw AC. The properdin system and immunity. I. Demonstration and isolation of a new serum protein, properdin, and its role in immune phenomena. Science (1954) 120:279-85. doi:10.1126/science.120.3112.279

3. Kouser L, Abdul-Aziz M, Nayak A, Stover CM, Sim RB, Kishore U. Properdin and factor h: opposing players on the alternative complement pathway “see-saw". Front Immunol (2013) 4:93. doi:10.3389/fimmu.2013.00093 commonly reported deficiency is the type I properdin deficiency that exhibits fulminant infections. The incidence of tuberculosis has not been reported in properdin deficient subjects, possibly due to the majority of studies being in Scandinavia or western Europe, in populations where there is a low incidence of tuberculosis.

The data in this study suggest that properdin, via TSR $4+5$, may help in the clearance of mycobacterial infection by circumventing pathogen immune evasion strategies by upregulating the pro-inflammatory response. Properdin may also promote the formation and maintenance of the protective granuloma. The data in this study give further insights into the involvement of complement regulatory proteins in shaping the cellular immune response against mycobacteria in a complement activation-independent manner. Further studies are needed to fully characterize the nature and extent of involvement of properdin in tuberculosis pathogenesis, particularly in the early stages of infection.

The complement-independent interaction between human properdin and mycobacteria is a novel observation, which is independent of $\mathrm{C} 3 \mathrm{~b}$ deposition and aggregation of properdin (61). This is consistent with our recent study where we have shown that properdin can recognize chemical patterns on nanoparticles via TSR $4+5$ and modulate immune response by THP-1 cells (26) without involving complement activation/deposition. In conclusion, properdin may be involved in modulating host-pathogen interactions in tuberculosis. However, further studies are needed on pathogenic $M$. tuberculosis and in vivo, to understand the precise role of this complement regulatory protein in pathogenesis, which may give new insights into therapies against this formidable disease.

\section{AUTHOR CONTRIBUTIONS}

MA-M, AT, MA-A, and LK carried out crucial experiments. SA, MNA-A, AAP, VM, EMG, AK, and RBS provided crucial reagents and expertise. $\mathrm{UK}, \mathrm{AT}$ and $\mathrm{LK}$ wrote the manuscript in addition to designing the experiments.

\section{FUNDING}

MA-A has been supported by the Ministry of Higher Education, Malaysia and the Universiti Sains Malaysia.

4. Smith CA, Pangburn MK, Vogel CW, Muller-Eberhard HJ. Molecular architecture of human properdin, a positive regulator of the alternative pathway of complement. J Biol Chem (1984) 259:4582-8.

5. Higgins JM, Wiedemann H, Timpl R, Reid KB. Characterization of mutant forms of recombinant human properdin lacking single thrombospondin type I repeats identification of modules important for function. J Immunol (1995) 155:5777-85.

6. Goundis D, Reid KB. Properdin, the terminal complement components, thrombospondin and the circumsporozoite protein of malaria parasites contain similar sequence motifs. Nature (1988) 335:82-5.

7. Kouser L, Abdul-Aziz M, Tsolaki AG, Singhal D, Schwaeble WJ, Urban $\mathrm{BC}$, et al. A recombinant two-module form of human properdin is an 
inhibitor of the complement alternative pathway. Mol Immunol (2016) 73:76-87. doi:10.1016/j.molimm.2016.03.005

8. Pangburn MK. Analysis of the natural polymeric forms of human properdin and their functions in complement activation. J Immunol (1989) 142:202-7.

9. Alcorlo M, Tortajada A, Rodriguez de Cordoba S, Llorca O. Structural basis for the stabilization of the complement alternative pathway C3 convertase by properdin. Proc Natl Acad Sci U S A (2013) 110:13504-9. doi:10.1073/ pnas. 1309618110

10. Gulati S, Agarwal S, Vasudhev S, Rice PA, Ram S. Properdin is critical for antibody-dependent bactericidal activity against Neisseria gonorrhoeae that recruit $\mathrm{C} 4 \mathrm{~b}$ binding protein. J Immunol (2012) 188:3416-25. doi:10.4049/jimmunol.1102746

11. Kimura Y, Miwa T, Zhou L, Song WC. Activator-specific requirement of properdin in the initiation and amplification of the alternative pathway complement. Blood (2008) 111:732-40. doi:10.1182/blood-2007-05-089821

12. Cortes C, Ferreira VP, Pangburn MK. Native properdin binds to Chlamydia pneumoniae and promotes complement activation. Infect Immun (2011) 79:724-31. doi:10.1128/IAI.00980-10

13. Ferreira VP, Cortes C, Pangburn MK. Native polymeric forms of properdin selectively bind to targets and promote activation of the alternative pathway of complement. Immunobiology (2010) 215:932-40. doi:10.1016/j.imbio.2010. 02.002

14. Saggu G, Cortes C, Emch HN, Ramirez G, Worth RG, Ferreira VP. Identification of a novel mode of complement activation on stimulated platelets mediated by properdin and $\mathrm{C} 3\left(\mathrm{H}_{2} \mathrm{O}\right)$. J Immunol (2013) 190:6457-67. doi:10.4049/ jimmunol.1300610

15. Carroll MV, Lack N, Sim E, Krarup A, Sim RB. Multiple routes of complement activation by Mycobacterium bovis BCG. Mol Immunol (2009) 46:3367-78. doi:10.1016/j.molimm.2009.07.015

16. Ali YM, Hayat A, Saeed BM, Haleem KS, Alshamrani S, Kenawy HI, et al. Low-dose recombinant properdin provides substantial protection against Streptococcus pneumoniae and Neisseria meningitidis infection. Proc Natl Acad Sci U S A (2014) 111:5301-6. doi:10.1073/pnas.1401011111

17. Tsolaki AG. Innate immune recognition in tuberculosis infection. Adv Exp Med Biol (2009) 653:185-97. doi:10.1007/978-1-4419-0901-5_13

18. Rooijakkers SH, van Strijp JA. Bacterial complement evasion. Mol Immunol (2007) 44:23-32. doi:10.1016/j.molimm.2006.06.011

19. Abdul-Aziz M, Tsolaki AG, Kouser L, Carroll MV, Al-Ahdal MN, Sim RB, et al. Complement factor $\mathrm{H}$ interferes with Mycobacterium bovis BCG entry into macrophages and modulates the pro-inflammatory cytokine response. Immunobiology (2016) 221:944-52. doi:10.1016/j.imbio.2016.05.011

20. Ferguson JS, Weis JJ, Martin JL, Schlesinger LS. Complement protein C3 binding to Mycobacterium tuberculosis is initiated by the classical pathway in human bronchoalveolar lavage fluid. Infect Immun (2004) 72:2564-73. doi:10.1128/IAI.72.5.2564-2573.2004

21. Ramanathan VD, Curtis J, Turk JL. Activation of the alternative pathway of complement by mycobacteria and cord factor. Infect Immun (1980) 29:30-5.

22. Cywes C, Godenir NL, Hoppe HC, Scholle RR, Steyn LM, Kirsch RE, et al. Nonopsonic binding of Mycobacterium tuberculosis to human complement receptor type 3 expressed in Chinese hamster ovary cells. Infect Immun (1996) 64:5373-83.

23. Hu C, Mayadas-Norton T, Tanaka K, Chan J, Salgame P. Mycobacterium tuberculosis infection in complement receptor 3-deficient mice. J Immunol (2000) 165:2596-602. doi:10.4049/jimmunol.165.5.2596

24. Schlesinger LS, Bellinger-Kawahara CG, Payne NR, Horwitz MA. Phagocytosis of Mycobacterium tuberculosis is mediated by human monocyte complement receptors and complement component C3. J Immunol (1990) 144: 2771-80

25. Cywes C, Hoppe HC, Daffé M, Ehlers MR. Nonopsonic binding of Mycobacterium tuberculosis to complement receptor type 3 is mediated by capsular polysaccharides and is strain dependent. Infect Immun (1997) 65:4258-66.

26. Kouser L, Paudyal B, Kaur A, Stenbeck G, Jones LA, Abozaid SM, et al. Human properdin opsonizes nanoparticles and triggers a potent pro-inflammatory response by macrophages without involving complement activation. Front Immunol (2018) 9:131. doi:10.3389/fimmu.2018.00131

27. Kemper C, Hourcade DE. Properdin: new roles in pattern recognition and target clearance. Mol Immunol (2008) 45:4048-56. doi:10.1016/j. molimm.2008.06.034
28. Kemper C, Atkinson JP, Hourcade DE. Properdin: emerging roles of a pattern-recognition molecule. Annu Rev Immunol (2010) 28:131-55. doi:10.1146/ annurev-immunol-030409-101250

29. Perdikoulis MV, Kishore U, Reid KB. Expression and characterisation of the thrombospondin type I repeats of human properdin. Biochim Biophys Acta (2001) 1548:265-77. doi:10.1016/S0167-4838(01)00238-2

30. Daigneault M, Preston JA, Marriott HM, Whyte MK, Dockrell DH. The identification of markers of macrophage differentiation in PMA-stimulated THP-1 cells and monocyte-derived macrophages. PLoS One (2010) 5:e8668. doi:10.1371/journal.pone.0008668

31. Al-Rayahi IA, Browning MJ, Stover C. Tumour cell conditioned medium reveals greater M2 skewing of macrophages in the absence of properdin. Immun Inflamm Dis (2017) 5:68-77. doi:10.1002/iid3.142

32. Xu W, Berger SP, Trouw LA, de Boer HC, Schlagwein N, Mutsaers C, et al. Properdin binds to late apoptotic and necrotic cells independently of $\mathrm{C} 3 \mathrm{~b}$ and regulates alternative pathway complement activation. J Immunol (2008) 180:7613-21. doi:10.4049/jimmunol.180.11.7613

33. Dixon KO, O’Flynn J, Klar-Mohamad N, Daha MR, van Kooten C. Properdin and factor $\mathrm{H}$ production by human dendritic cells modulates their $\mathrm{T}$-cell stimulatory capacity and is regulated by IFN-gamma. Eur J Immunol (2017) 47:470-80. doi:10.1002/eji.201646703

34. Narni-Mancinelli E, Gauthier L, Baratin M, Guia S, Fenis A, Deghmane AE, et al. Complement factor $\mathrm{P}$ is a ligand for the natural killer cell-activating receptor NKp46. Sci Immunol (2017) 2(10):eaam9628. doi:10.1126/sciimmunol.aam 9628

35. Agarwal S, Specht CA, Haibin H, Ostroff GR, Ram S, Rice PA, et al. Linkage specificity and role of properdin in activation of the alternative complement pathway by fungal glycans. MBio (2011) 2(5):e00178-11. doi:10.1128/ mBio.00178-11

36. Russell DG. Mycobacterium tuberculosis: here today, and here tomorrow. Nat Rev Mol Cell Biol (2001) 2:569-77. doi:10.1038/35085034

37. Feng CG, Kaviratne M, Rothfuchs AG, Cheever A, Hieny S, Young HA, et al. NK cell-derived IFN-gamma differentially regulates innate resistance and neutrophil response in T cell-deficient hosts infected with Mycobacterium tuberculosis. J Immunol (2006) 177:7086-93. doi:10.4049/jimmunol.177.10. 7086

38. Eum SY, Kong JH, Hong MS, Lee YJ, Kim JH, Hwang SH, et al. Neutrophils are the predominant infected phagocytic cells in the airways of patients with active pulmonary tuberculosis. Chest (2010) 137:122-8. doi:10.1378/ chest.09-0903

39. Smith D, Hansch H, Bancroft G, Ehlers S. T-cell-independent granuloma formation in response to Mycobacterium avium: role of tumour necrosis factoralpha and interferon-gamma. Immunology (1997) 92:413-21. doi:10.1046/ j.1365-2567.1997.00384.x

40. Algood HM, Chan J, Flynn JL. Chemokines and tuberculosis. Cytokine Growth Factor Rev (2003) 14:467-77. doi:10.1016/S1359-6101(03)00054-6

41. Ehlers S, Schaible UE. The granuloma in tuberculosis: dynamics of a hostpathogen collusion. Front Immunol (2012) 3:411. doi:10.3389/fimmu.2012.00411

42. Dannenberg AM Jr. Delayed-type hypersensitivity and cell-mediated immunity in the pathogenesis of tuberculosis. Immunol Today (1991) 12:228-33. doi:10.1016/0167-5699(91)90035-R

43. Sanghi S, Grewal RS, Vasudevan B, Lodha N. Immune reconstitution inflammatory syndrome in leprosy. Indian J Lepr (2011) 83:61-70.

44. Huaux F, Lo Re S, Giordano G, Uwambayinema F, Devosse R, Yakoub Y, et al. IL-1 $\alpha$ induces $\mathrm{CD} 11 \mathrm{~b}$ (low) alveolar macrophage proliferation and maturation during granuloma formation. J Pathol (2015) 235(5):698-709. doi:10.1002/ path. 4487

45. Mayer-Barber KD, Barber DL, Shenderov K, White SD, Wilson MS, Cheever A, et al. Caspase-1 independent IL-1beta production is critical for host resistance to Mycobacterium tuberculosis and does not require TLR signaling in vivo. J Immunol (2010) 184:3326-30. doi:10.4049/jimmunol.0904189

46. Correia JW, Freitas MV, Queiroz JA, PereiraPerrin M, Cavadas B. Interleukin-6 blood levels in sensitive and multiresistant tuberculosis. Infection (2009) 37:138-41. doi:10.1007/s15010-008-7398-3

47. Leal IS, Smedegard B, Andersen P, Appelberg R. Interleukin-6 and interleukin-12 participate in induction of a type 1 protective T-cell response during vaccination with a tuberculosis subunit vaccine. Infect Immun (1999) 67:5747-54. 
48. Appelberg R, Castro AG, Pedrosa J, Minoprio P. Role of interleukin-6 in the induction of protective $\mathrm{T}$ cells during mycobacterial infections in mice. Immunology (1994) 82:361-4.

49. Bhatt K, Salgame P. Host innate immune response to Mycobacterium tuberculosis. JClin Immunol (2007) 27:347-62. doi:10.1007/s10875-0079084-0

50. Shaw TC, Thomas LH, Friedland JS. Regulation of IL-10 secretion after phagocytosis of Mycobacterium tuberculosis by human monocytic cells. Cytokine (2000) 12:483-6. doi:10.1006/cyto.1999.0586

51. O'Leary S, O'Sullivan MP, Keane J. IL-10 blocks phagosome maturation in Mycobacterium tuberculosis-infected human macrophages. Am J Respir Cell Mol Biol (2011) 45:172-80. doi:10.1165/rcmb.2010-0319OC

52. Moore KW, de Waal Malefyt R, Coffman RL, O'Garra A. Interleukin-10 and the interleukin-10 receptor. Annu Rev Immunol (2001) 19:683-765. doi:10.1146/ annurev.immunol.19.1.683

53. Gazzinelli RT, Oswald IP, James SL, Sher A. IL-10 inhibits parasite killing and nitrogen oxide production by IFN-gamma-activated macrophages. J Immunol (1992) 148:1792-6.

54. Almeida AS, Lago PM, Boechat N, Huard RC, Lazzarini LC, Santos AR, et al. Tuberculosis is associated with a down-modulatory lung immune response that impairs Th1-type immunity. J Immunol (2009) 183:718-31. doi:10.4049/ jimmunol.0801212

55. Barnes PF, Lu S, Abrams JS, Wang E, Yamamura M, Modlin RL. Cytokine production at the site of disease in human tuberculosis. Infect Immun (1993) 61:3482-9.

56. Ranaivomanana P, Raberahona M, Rabarioelina S, Borella Y, Machado A, Randria MJD. Cytokine biomarkers associated with human extra-pulmonary tuberculosis clinical strains and symptoms. Front Microbiol (2018) 9:275. doi:10.3389/fmicb.2018.00275
57. Aly S, Mages J, Reiling N, Kalinke U, Decker T, Lang R, et al. Mycobacteriainduced granuloma necrosis depends on IRF-1. JCell Mol Med (2009) 13:2069-82. doi:10.1111/j.1582-4934.2008.00470.x

58. Rook GA. Th2 cytokines in susceptibility to tuberculosis. Curr Mol Med (2007) 7:327-37. doi:10.2174/156652407780598557

59. Gordon SV, Brosch R, Billault A, Garnier T, Eiglmeier K, Cole ST. Identification of variable regions in the genomes of tubercle bacilli using bacterial artificial chromosome arrays. Mol Microbiol (1999) 32:643-55. doi:10.1046/j.1365-2958.1999.01383.x

60. Brodin P, Majlessi L, Marsollier L, de Jonge MI, Bottai D, Demangel C, et al. Dissection of ESAT-6 system 1 of Mycobacterium tuberculosis and impact on immunogenicity and virulence. Infect Immun (2006) 74:88-98. doi:10.1128/ IAI.74.1.88-98.2006

61. Harboe M, Johnson C, Nymo S, Ekholt K, Schjalm C, Lindstad JK, et al. Properdin binding to complement activating surfaces depends on initial $\mathrm{C} 3 \mathrm{~b}$ deposition. Proc Natl Acad Sci U S A (2017) 114(4):E534-9. doi:10.1073/ pnas. 1612385114

Conflict of Interest Statement: The authors declare that the research was conducted in the absence of any commercial or financial relationships that could be construed as a potential conflict of interest.

Copyright (C) 2018 Al-Mozaini, Tsolaki, Abdul-Aziz, Abozaid, Al-Ahdal, Pathan, Murugaiah, Makarov, Kaur, Sim, Kishore and Kouser. This is an open-access article distributed under the terms of the Creative Commons Attribution License (CC BY). The use, distribution or reproduction in other forums is permitted, provided the original author(s) and the copyright owner are credited and that the original publication in this journal is cited, in accordance with accepted academic practice. No use distribution or reproduction is permitted which does not comply with these terms. 